\title{
Application of CVaR Risk Aversion Approach in the Dynamical Scheduling Optimization Model for Virtual Power Plant Connected with Wind-Photovoltaic-Energy Storage System with Uncertainties and Demand Response
}

\author{
Zhongfu Tan ${ }^{1}$, Guan Wang ${ }^{1}$, Liwei Ju${ }^{1}$, Qingkun Tan ${ }^{1}$, Wenhai Yang ${ }^{1}$ \\ ${ }^{1}$ North China Electric Power University, Beijing, China, 102206 \\ Corresponding author: Liwei Ju; E-mail: Liwei_Ju@ncepu.edu.cn (L.W.Ju) \\ Tel.:+86 10 18911639155; fax: +861061773118 \\ Address: North China Electric Power University, Chang Ping District, Beijing, 102206, China.
}

\begin{abstract}
Conditional value at risk (CVaR) and confidence degree theory are introduced to build scheduling model for VPP connecting with wind power plant (WPP), photovoltaic generators (PV), convention gas turbine (CGT), energy storage systems (ESSs) and incentive-based demand response (IBDR). Latin hypercube sampling method and Kantorovich distance are introduced to construct uncertainties analysis method. A risk aversion scheduling model is proposed with minimum CVaR objective considering maximum operation revenue. The IEEE30 bus system is used as simulation system. Results show: (1) Price-based demand response could realize peak load shifting, ESSs and IBDR could increase operation revenue. (2) Threshold $\alpha$ reflects risk attitude of decision maker, which has strong risk tolerant to gain the excess income with low $\alpha$. (3) In peak period, decision maker would reduce WPP and PV for avoiding power shortage loss. Otherwise, WPP and PV would be called in priority since system reserve capacity is sufficient. (4) When $0.85 \leq \boldsymbol{\beta}<0.95$, the decreasing slope of CVaR value is big, decision maker is sensitive on risk. When $\boldsymbol{\beta} \geq 0.95$, VPP scheduling scheme reach the most conservative, net revenue and CVaR value are $¥ 8995.34$ and $¥ 18834$. Therefore, the proposed model could describe VPP risk and provide decision support tool for decision maker.
\end{abstract}

Key words: CVaR method; virtual power plant; demand response; risk aversion; dynamical scheduling

\section{Introduction}

Energy shortage and environment pollution problems promote power industry put more attention in renewable energy power generation. Renewable energy power generation makes full use of wind energy, solar energy and hydro energy. They are playing increasingly important roles in energy structures with small pollutant emission, high efficiency and less transmission cost [1]. However, limited by small installed capacity, large quantity and decentralized distribution, distributed generators (DGs) has high grid connection cost [2], what's more, the volatility of DG output affects the stable operation of power grid [3].Virtual power plant (VPP) integrates DGs, energy storage systems (ESSs), controllable load and distributed energy resources (DERs) using refined control method and energy management [4], which can realize effective DG integration and polymerization [5]. 
The concept of VPP attracts domestic and foreign attentions. From 2001 to 2005, virtual fuel cell power plant project was co-founded by Germany Government and Spain Government [6]. In 2007, Holland established a VPP program constituted by 10 co-generation of heat and power (CHP) units [7]. Cassel University integrated wind turbine, solar photovoltaic system, biogas power station and hydro power plant into VPP [8]. From 2005 to 2008, Britain, Spain and France established a flexible electricity network to integrate energy solution program for the sustainable development of Europe power supply system [9]. From 2009 to 2012, Denmark and Germany established electric vehicle in a distributed and integrated market using sustainable energy and open networks program [10]. In 2014, the wind-photovoltaic-hydro distributed demonstration project of China national electric power group corporation successfully connected into the grid and operate in Yunnan province [11]. From 2010 to 2015, Europe finished WEB2ENERRGY program, implemented intelligent energy management and power distribution automatic technology in smart power distribution [12].

Researches on VPP mainly include capacity configuration, coordinated operation and benefit improvement [13]. Wind power plant (WPP) and solar photovoltaic power (PV) are VPP's important components [14]. To reduce the fluctuation impact of WPP and PV, convention gas turbine (CGT), ESSs, electric vehicles and other controllable DGs are used as supplemental power source [15]. Hrpoko et al. [16] studied scheduling model for VPPs consist of WPP, PV, hydro power and battery energy storage. Peik-Herfeh et al. [17] built a scheduling optimization model for VPP operation. Pandzic etal. [18] put forward mid-term dispatch for VPP consist of WPP, PV, CGT and pumped storage power. Zapata et al. [19] integrated several cogeneration devices and PV installations into VPP, and compared and analyzed the imbalance reduction strategies for virtual power plant operation. Carrion et al. [20] analyzed the coordinated scheduling and cost-effectiveness of small-scale flexible nuclear power plant and offshore wind farm. In literature [13-20], WPP, PV, CGT, pumped storage power, ESSs, biomass power, nuclear power and heat power installations are the main components of VPP. They all locate in power generation side. In recent years, the development of Smart Grid has provided a platform for demand side to participate into power generation scheduling [21]. Incentive-based DR (IBDR) could participate into energy/reserve market in the form of interruptible load and controllable load [22]. Price-based DR (PBDR) uses differentiated power price to guide customer rational electricity consumption and coordinate with VPP in grid connection [23]. Stjepan et al. [24] studied the optimization scheme for VPP power declaration, which is composed of wind power and flexible load. Wang et al. [25] have discussed the operation modes of VPP with interruptible loads. Erdinc. [26] has analyzed the economic impacts of small-scale own generating and storage units and electric vehicles under different demand response strategies for smart households.

The fluctuations of renewable energy output and demand load as well as other uncertainty factors may cause big deviation between scheduling plan and real-time operation strategy [27]. In order to meet system operation constraints, reasonable scheduling mode should be used to reduce the influence of uncertainty factors. How to improve VPP operation income has become the key problem [28]. Moghaddam et al. [29] described WPP and PV into linear combination in five typical scenarios. Saeed et al.[30] used two-point estimation method to estimate the volatility of output power. Molderink et al. [31] used the maximum 
likelihood estimation to estimate wind speed distribution parameters. Yang et al. [32] introduced stochastic chance constrained planning and built VPP scheduling model considering the uncertainty of WPP, PV and demand load. Ju et al. [33] used the robust stochastic method to describe the uncertainty factors and built a stochastic scheduling model. Mohammad et al. [34] addressesed the optimal operation of VPP considering the risk factors. Tascikaraoglu et al. [35] proposed an economic operation-based load dispatching scheme, which can interactively adapt to really measure WPP and PV. The above literatures have already discussed the problems of VPP coordinate operation and how to overcome the uncertainty factors.

However, note that there are some insufficiencies on VPP optimization operation. Firstly, some studies have considered the operation strategies of interruptible load, a main way of incentive-based demand response (IBDR), but most of them take the interruptible load price as a fixed value. In fact, IBDR is mainly step-by-step provided by demand response providers (DRPs) according to demand response (DR) price. What's more, there are few studies on how to utilize price-based demand response (PBDR) and improve VPP operation. Secondly, most studies only discuss the uncertainty factors of WPP and PV without considering demand load. Although, few literatures consider load uncertainty, but they mainly take the expected value of demand load as input data. This will bring potential risk for VPP operation. Thirdly, robust stochastic theory, chance constrained programming and scenario simulation method are used to describe uncertainty factors. However, robust stochastic theory could only describe the uncertainty factors in constraint conditions. Chance constrained programming method could describe uncertainty factors in objective function, but could not limit the expected revenue of decision makers. Scenario simulation method takes regression analysis with historical data to get the distribution function. But different scenario reduction strategies would make big difference. All above analysis motivates us to put forward a risk aversion model for VPP scheduling. The main contributions of this work are summarized as follows:

- WPP, PV, CGT, ESSs and IBDR are integrated into VPP. In order to analyze the uncertainties of WPP, PV and demand load, Latin hypercube sampling method and Kantorovich distance are introduced to construct uncertainties scenario simulation method and reduction technology. PBDR is used to guide customers' reasonable power consumption and coordinate with VPP power generation. WPP, PV and CGT are used to meet demand load. ESSs and IBDR are used to provide reserve service.

- Basic scheduling model for VPP optimal operation with PBDR is proposed with the objective of the maximum expected net revenue value, which takes load supply-demand balance constraint, demand response constraint, system reserve capacity constraint and DG output constraints as constraint conditions. The expected net revenue of VPP operation is calculated according to the probability and value of simulation scenarios, which could provide the threshold value for risk analysis and decision.

- Risk aversion model for VPP optimal operation is proposed based on CVaR method and confidence degree theory, which take the minimum CVaR value considering maximum revenue of VPP operation as the optimization objective. The risk threshold value and confidence degree level could be used to reflect risk attitude of decision maker, which could provide a flexible tool for risk decision and gaining the optimal balance point between risk and income of VPP operation.

The rest of this manuscript is organized as follows: Section 2 describes the basic structure of VPP, 
proposes power output mode and DR analysis mode. Section 3 put forwards the uncertainty simulation analysis model and introduce the CVaR theory. The risk aversion model for VPP optimization operation is proposed in Section 4, include three parts: basic scheduling model, risk aversion model and solution methodology. The risk aversion model takes the minimum CVaR value considering maximum revenue of VPP operation as the optimization objective. Section 6 takes the improved IEEE30 bus system as the simulation system. Section 7 highlights the contributions and conclusions of this manuscript.

\section{VPP structure description}

\subsection{VPP participants}

In this study, CGT, WPP, PV, ESSs and IBDR are integrated into VPP. IBDR provided by DRPs could participate in energy scheduling by load reduction and reserve scheduling by reserve capacity [33]. PBDR are scheduled by independent scheduling operation (ISO), which could change customers' power consumption behavior and optimize load demand curve by implementing TOU price. Demand load contains sensitive load, interruptible load and adjustable load etc. The sensitive load reflects a relatively stable electricity consumption behavior and hard to participate into DR. Interruptible load mainly participate into VPP power generation in IBDR mode. Adjustable load can participate into VPP power generation in both PBDR and IBDR mode. Fig.1 draws the basic structure of VPP.

Fig.1 The basic structure of VPP

In VPP, the power generation nature for WPP, PV, CGT and DR is different, therefore, the output of PV, WPP and CGT should be converted into the direct-current (DC) for power convergence, then converted into alternating current (AC) for satisfying customer demand load[36]. Meanwhile, customer demand load is mainly satisfied by the output of WPP and PV, the surplus load is supplemented by CGT. However, since the output of WPP and PV is uncertainty, system scheduling is pre-scheduling, which has to achieve a determined system scheduling scheme before knowing the actual output. In order to overcome the uncertainties, ESSs are mainly used to provide reserve service for WPP and PV. The surplus reserve service is supplemented by CGT since CGT units with the characteristic of fast start-stop. IBDR provide power output by changing their electricity consumption behavior, which and participate into energy market and reserve service market. IBDR could promote the power generation and grid connection of wind power and solar photovoltaic. PBDR could decrease demand load in power demand-supply tension periods and provide system reserve service.

\subsection{Power output model}

The uncertainty factors of VPP main contain the uncertainty factors from wind power, solar photovoltaic power and demand load. In order to analyze the uncertainty influence, the probability density functions (PDF) for WPP output, PV output and demand load should be proposed.

\subsubsection{WPP output}

The uncertainty of wind power output is mainly caused by wind velocity uncertainty. Literature [14] proves wind velocity could be described by the Weibull distribution as equation (1): 


$$
f(v)=\frac{\varphi}{\vartheta}\left(\frac{v}{\vartheta}\right)^{\varphi-1} e^{-(v / c)^{\varphi}}
$$

According to Eq.(1), PDF of wind velocity could be calculated. Then, WPP output could be calculated by Eq.(2)

$$
g_{W P P, t}=\left\{\begin{array}{lc}
0, & 0 \leq v_{t}<v_{\text {in }}, \quad v_{t}>v_{\text {out }} \\
\frac{v_{t}-v_{\text {in }}}{v_{\text {rated }}-v_{\text {in }}} g_{R}, & v_{\text {in }} \leq v_{t} \leq v_{\text {rated }} \\
g_{R}, & v_{\text {rated }} \leq v_{t} \leq v_{\text {out }}
\end{array}\right.
$$

\subsubsection{PV output}

The output of solar photovoltaic power mainly depends on solar irradiance. Literature [33] proves that solar irradiance could be described by the Beta distribution as follows:

$$
f(\theta)= \begin{cases}\frac{\Gamma(\xi) \Gamma(\psi)}{\Gamma(\xi)+\Gamma(\psi)} \theta^{\xi-1}(1-\theta)^{\psi-1} & , 0 \leq \theta \leq 1, \xi \geq 0, \psi \geq 0 \\ 0 & , \text { otherwise }\end{cases}
$$

If mean value $\mu$ and standard deviation $\sigma$ of the irradiance could be gained by statistical data. Then shape parameters $\xi$ and $\psi$ of Beta distribution could be calculated as follows:

$$
\begin{gathered}
\psi=(1-\mu) \times\left(\frac{u \times(1+\mu)}{\sigma^{2}}-1\right) \\
\xi=\frac{\mu \times \psi}{1-u}
\end{gathered}
$$

The PDF of solar irradiance could be calculated by Eq.(3), then, PV output mainly is determined by the area of photovoltaic panels and energy conversion efficiency. The detailed calculation equation is:

$$
g_{P V, t}=\eta_{P V} \times S_{P V} \times \theta_{t}
$$

\subsection{DR analysis model}

The demand load has great uncertainty, which could be described by dividing demand load into load prediction results and prediction error as shown in equation (7):

$$
L_{t}=L_{t}^{\mathrm{f}}+L_{t}^{\mathrm{e}}
$$

Assume the prediction error obeys normal distribution $L_{t}^{\mathrm{e}} \sim\left[0, \delta_{L, t}^{2}\right]$ [37]. Demand load obeys normal distribution $L_{t} \sim\left[L_{t}^{\mathrm{f}}, \delta_{L, t}^{2}\right]$. Demand load distribution function is a continuous function according to equation (7). However, in actual power generation scheduling, demand load in each time point should be cleared. The distribution function should be a discrete function. The interval method divides distribution function into multiple subintervals and regards some points in a subinterval as the demand load of this subinterval [38]. Fig. 2 is the discretization method of demand load distribution function.

Fig. 2 The discretization method for demand load distribution function

In general, demand load contains sensitive load, interruptible load and adjustable load etc. DR could 
optimize customer behavior by implementing differential price mechanism according to demand load distribution or the related incentive compensation policies. Demand response could be divided into PBDR and IBDR. For different types of demand load, sensitive load reflects a relatively stable electricity consumption behavior and hard to participate into DR. Interruptible load mainly participate into VPP power generation in IBDR. Adjustable load can participate into VPP power generation in both PBDR and IBDR. The study about DR has already been carried out in our previous literature [39]. Therefore, this manuscript does not introduce model evolutionary process and directly use the final demand response model, the cost model of PBDR and IBDR could be calculated as follows:

$$
\begin{aligned}
& \pi_{t}^{\mathrm{PB}}=P_{t}^{0} L_{t}^{0}-\left(P_{t}^{0}+\Delta P_{t}\right) L_{t}=P_{t}^{0} L_{t}^{0}-P_{t} L_{t} \\
& L_{t}=L_{t}^{0} \times\left\{1+e_{t t} \times \frac{\left[P_{t}-P_{t}^{0}\right]}{P_{t}^{0}}+\sum_{\substack{s=1 \\
s \neq t}}^{24} e_{s t} \times \frac{\left[P_{s}-P_{s}^{0}\right]}{P_{s}^{0}}\right\}
\end{aligned}
$$

When $s=t, e_{s t}$ is called self-elasticity. Only demand curtailment could occur, with which $e_{s t}$ is always negative. Then, load change is always a negative amount, when $s \neq t, e_{s t}$ is called cross-elasticity. Demand shifting could occur. In this case, $e_{s t}$ is always positive. Then, the load change is always a positive amount.

In the IBDR program, Only load change can occur without load shifting. IBDR programs can participate in energy scheduling by load reduction and reserve scheduling by reserve capacity [23]. DRPs could participate into energy scheduling and reserve scheduling by providing equivalent output, which could be positive or negative. The costs of DPRs participating in energy scheduling and reserve scheduling could be calculated by Eq. (10).

$$
\pi_{t}^{\mathrm{IB}}=\sum_{i}^{I} \rho_{i, t}^{E} \cdot \Delta L_{i, t}^{E}+\sum_{i}^{I} \rho_{i, t}^{R, d n} \cdot \Delta L_{i, t}^{R, d n}+\sum_{i}^{I} \rho_{i, t}^{R, d n} \cdot \Delta L_{i, t}^{R, u p}
$$

IBDR is mainly provided by demand response providers (DRPs). Only load change can occur in IBDR without load shifting. IBDR can participate in energy scheduling by load reduction and reserve scheduling by reserve capacity.

\section{Uncertainty simulation analysis}

In order to overcome uncertainty of virtual power plant, uncertainty should be handled from two aspects of uncertainty simulation and uncertainty quantitative analysis.

\subsection{Uncertainty simulation}

Traditional scenario generation method mainly uses Monte Carlo method to sample from probability distribution by using random number or pseudo-random number, which has good suitability and accuracy. But when the distribution contains results with low probability, samples with a small sample is hard to represent its probability, while big sample would take much time [38]. Latin Hypercube Sampling method stratifies the input probability and divides the cumulative probability curve into equal intervals. Then, sample from each interval of the cumulative probability curve. The sampling results would be forces to be the representative of each interval and the input distribution probability would be rebuilt [39]. LHS method 
ensures the small probability event be represented by force the sampling result to contain small probability event, which could overcome the shortage of Monte Carlo method. The detailed process of LHS method in random variable scenario simulation refers to literature [40].

LHS method would be applied to generate random variable scenario set. If the uncertainty factors are independent to each other, then the probability of each scenario equal the multiplication of each uncertainty factors. Though the scenario set generated by LHS contain various possible scenarios of the random variables, some scenarios are similar to each other, and overlap would exist in the scenario set. To get the typical scenario set, the initial scenario should be reduced. Researches about scenario reduction has already implemented in our previous work [33], which introduces Kantorovich distance method to build scenario reduction method, delete those scenarios with minimum K-distance. The detailed scenario reduction steps refer to literature [40]. Fig. 3 shows the process of scenario reduction.

Fig. 3 The process of scenario simulation and reduction for uncertainty factors

\subsection{Uncertainty analysis}

The risk quantitative analysis is necessary for VPP to avoid operation risk. Value at risk (VaR) [41] quantitatively analyzed risk characteristic by calculating the maximum possible loss of investment portfolios in normal market condition with determined time zone. However, VaR can only calculate the risk under certain confidence degree level and does not consider tail condition, which has some limitations in practical application. CVaR can describe risk distribution statue outside the confidence degree level [41], the basic theory can be described as:

Assume $\boldsymbol{X}$ is the portfolio vector, random vector $\boldsymbol{Y} \in \boldsymbol{R}^{m}$ represents the random factor, where $\boldsymbol{R}^{m}$ is $m$-dimension space. The loss function of $\boldsymbol{X}$ could be described as $f(\boldsymbol{X}, \boldsymbol{Y})$. Assume the joint probability density function of $\boldsymbol{Y}$ is $p(\boldsymbol{Y})$. For a given $\boldsymbol{X}, f(\boldsymbol{X}, \boldsymbol{Y})$ will not exceed the threshold $\alpha$ determined by $\boldsymbol{Y}$, which can be calculated by Eq. (11), where $\alpha$ is a given loss level.

$$
\psi(\boldsymbol{X}, \alpha)=\int_{f(\boldsymbol{X}, \boldsymbol{Y}) \leq \alpha} p(\boldsymbol{Y}) d \boldsymbol{Y}
$$

Wherein, $\boldsymbol{X} \in \boldsymbol{\Omega}, \boldsymbol{\Omega}$ is a subset of $n$-dimension real-number space $\boldsymbol{R}^{n}$ and represents the feasible set of the portfolio. $\psi(\boldsymbol{X}, \alpha)$ is the distribution function of the cumulative loss with portfolio vector $\boldsymbol{X}$. Literature [42] proves $\psi(X, \alpha)$ is a right continuous and non-decreasing function about $\alpha$. Then, the CVaR value of the portfolio problem could be calculated by equation (12)[41]:

$$
F_{\beta}(\boldsymbol{X}, \alpha)=\alpha+\frac{1}{1-\beta} \int_{\boldsymbol{Y} \in \boldsymbol{R}^{m}}(f(\boldsymbol{X}, \boldsymbol{Y})-\alpha)^{+} p(\boldsymbol{Y}) d \boldsymbol{Y}
$$

Wherein, $\beta$ is confidence degree. $F_{\beta}(\boldsymbol{X}, \alpha)$ represents $\mathrm{CVaR}$ value of the portfolio problem under confidence degree $\beta$ when the loss $f(\boldsymbol{X}, \boldsymbol{Y})$ does not exceed the threshold. $(f(\boldsymbol{X}, \boldsymbol{Y})-\alpha)^{+}$is the value of $\max \{f(\boldsymbol{X}, \boldsymbol{Y})-\alpha, 0\}$. When the analytical expression of $p(\boldsymbol{Y})$ is hard to get directly, the historical data of $\boldsymbol{Y}$ and Monte Carlo method would be used to estimate the integral term in equation (13). Set 
$Y_{1}, Y_{2}, \cdots, Y_{N}$ as $N$ examples of $\boldsymbol{Y}$, then the estimation value of $F_{\beta}(\boldsymbol{X}, \alpha)$ is:

$$
\hat{F}_{\beta}(\boldsymbol{X}, \alpha)=\alpha+\frac{1}{N(1-\beta)} \sum_{k=1}^{N}(f(\boldsymbol{X}, \boldsymbol{Y})-\alpha)^{+}
$$

Wherein, $\hat{F}_{\beta}(X, \alpha)$ is the estimation value of $F_{\beta}(X, \alpha)$.

\section{Risk aversion optimization model}

In order to minimize the uncertainty influence, CVaR method and confidence degree theory is introduced to construct risk aversion model for VPP optimal operation.

\subsection{Basic scheduling model}

Basic scheduling model for VPP did not consider the uncertainty risk with the maximum objective of VPP operation net revenue, which could provide the threshold value for risk evaluation.

\subsubsection{Objective function}

Power generation for VPP with wind power, solar photovoltaic power and energy storage system, the maximum VPP operation income is taken as the objective function as equation (14):

$$
\begin{gathered}
\max f\left(\boldsymbol{g}_{V P P, t}\right)=R\left(\boldsymbol{g}_{V P P, t}\right)-C\left(\boldsymbol{g}_{V P P, t}\right) \\
R\left(\boldsymbol{g}_{V P P, t}\right)=\sum_{t=1}^{T} \sum_{k=1}^{K} \rho_{k}\left(P_{W P P, t} g_{W P P, t}+P_{P V, t} g_{P V, t}+P_{E S S, t} g_{E S S, t}+P_{C G T, t} g_{C G T, t}\right)_{k} \\
C\left(\boldsymbol{g}_{V P P, t}\right)=\sum_{t=1}^{T} \sum_{k=1}^{k} \rho_{k}\left[\rho_{E S S, t}^{c h r} g_{E S S, t}^{c h r}+\left(\pi_{C G T, t}^{p g}+\pi_{C G T, t}^{s S}\right)+\left(\pi_{t}^{\mathrm{PB}}+\pi_{t}^{\mathrm{IB}}\right)+\rho_{U G, t} g_{U G, t}\right]_{k}
\end{gathered}
$$

Eq.(15) and Eq.(16) calculate the revenue and cost of VPP operation, respectively. The VPP operation cost includes operation cost and startup-shutdown cost of CGT, which could be calculated by Eq.(17) to Eq.(19),the detailed is as follows:

$$
\begin{gathered}
\pi_{C G T, t}^{p g}=a_{C G T}+b_{C G T} g_{C G T}+c_{C G T}\left(g_{C G T, t}\right)^{2} \\
\pi_{C G T, t}^{s s}=\left[u_{C G T, t}\left(1-u_{C G T, t}\right)\right] D_{C G T, t} \\
D_{C G T, t}=\left\{\begin{array}{l}
N_{C G T}^{h o t}, T_{C G T}^{\mathrm{min}}<T_{C G T, t}^{\mathrm{off}} \leq T_{C G T}^{\mathrm{min}}+T_{C G T}^{c o l d} \\
N_{C G T}^{\text {cold }}, T_{C G T, t}^{\mathrm{off}}>T_{C G T}^{\mathrm{min}}+T_{C G T}^{\text {cold }}
\end{array}\right.
\end{gathered}
$$

In Eq.(18) $u_{C G T, t}$ is operation statue of CGT, 0-1 variable, when $u_{C G T, t}=1$ means CGT is in operation. When $u_{C G T, t}=0$ means CGT is not in operation.

\subsubsection{Constraint conditions}

The operation of VPP must meet load supply and demand balance constraint, gas turbine operation constraint, wind power and solar photovoltaic power output constraint, demand response constraint and system spinning reserve constraint etc.

(1) Supply-demand load balance constraint

Load supply and demand balance without demand response: 


$$
\underbrace{g_{W P P, t}\left(1-\varphi_{W P P}\right)+g_{P V, t}\left(1-\varphi_{P V}\right)+\left(g_{E S S, t}^{\text {dis }}-g_{E S, t}^{\text {chr }}\right)+g_{C G T, t}\left(1-\varphi_{C G T}\right)}_{\text {VPP output in day - ahead scheduling }}+g_{G C, t}=L_{t}^{0}
$$

Load supply and demand balance with demand response:

$$
\underbrace{\left[\begin{array}{c}
g_{W P P, t}\left(1-\varphi_{W P P}\right)+g_{P V, t}\left(1-\varphi_{P V}\right)+ \\
\left(g_{E S S, t}^{\text {dis }}-g_{E S S, t}^{\text {chr }}\right)+g_{C G T, t}\left(1-\varphi_{C G T}\right)
\end{array}\right]}_{\text {VPP output in day-ahead scheduling }}+g_{G C, t}+\sum_{i=1}^{I}\left(\Delta L_{i, t}^{E}+\Delta L_{i, t}^{R, d n}\right)=L_{t}+\sum_{i=1}^{I}\left(\Delta L_{i, t}^{R, u p}\right)
$$

(1) Demand response constraint

- PBDR operation constraints

Since load shifting and load curtailment can both occur in PBDR, in order to smooth load demand curve, load change produced by PBDR should meet the following constraints

$$
\begin{gathered}
\left|\Delta L_{P B, t}\right| \leq u_{P B, t} \Delta L_{P B, t}^{\max } \\
u_{P B, t} \Delta \underline{L}_{P B} \leq \Delta L_{P B, t}-\Delta L_{P B, t-1} \leq u_{P B, t} \Delta \bar{L}_{P B} \\
\sum_{t=1}^{T} \Delta L_{P B, t} \leq \Delta L_{P B}^{\max }
\end{gathered}
$$

Wherein, $u_{P B, t}$ is status variable of PBDR operation, $0-1$ variable, when $u_{P B, t}=1$ means PBDR is implemented, whereas $u_{P B, t}=0$ means PBDR is not implemented. When $\Delta L_{P B, t}$ is positive, load is shifting or curtailing, otherwise, load is increasing from other hours of load shifting.

- IBDR operation constraints

$$
\begin{gathered}
D_{i}^{j, \min } \leq \Delta L_{i, t}^{j} \leq D_{i, t}^{j}, j=1 \\
0 \leq \Delta L_{i, t}^{j} \leq\left(D_{i, t}^{j}-D_{i, t}^{j-1}\right), j=2,3, \ldots, \mathrm{J} \\
\Delta L_{i, t}^{E}=\sum_{j=1}^{J} \Delta L_{i, t}^{j}
\end{gathered}
$$

In order to gentle demand load curve and avoid the phenomenon peak-valley upside down, DR program should meet the following constraints:

$$
\begin{aligned}
& \Delta L_{i, t}^{E}+\Delta L_{i, t}^{R, d n} \leq D_{i}^{\max } \\
& \Delta L_{i, t}^{E}-\Delta L_{i, t}^{R, u p} \geq D_{i}^{\min }
\end{aligned}
$$

In the studied VPP, IBDR is considered as part of VPP, load changed produced by IBDR could be regarded as "virtual generation (VG) unit". To avoid excessive volatility, VG unit should meet the following constraints: demand load

$$
\begin{aligned}
& {\left[X_{t-1}^{\text {on }}-T_{\mathrm{U}}\right]\left(u_{I B, t-1}-u_{I B, t}\right) \geq 0,} \\
& {\left[X_{t}^{\text {off }}-T_{\mathrm{D}}\right]\left(u_{I B, t}-u_{I B, t-1}\right) \geq 0,}
\end{aligned}
$$

Wherein, $u_{I B, t}$ is status variable of IBDR operation, when $u_{I B, t}=1$ means IBDR in operation.

(3) System spinning reserve constraint

To reduce the influence of uncertainty factors on VPP stable operation, system should set 
corresponding reverse capacity, namely upwards/downward spinning reserves.

$$
\begin{gathered}
g_{V P P}^{\max }-g_{V P P, t}+\Delta L_{P B, t}+\sum_{i=1}^{I} \Delta L_{i, t}^{E} \geq r_{1} \cdot L_{t}+r_{W P P}^{u p} \cdot g_{W P P, t}+r_{W P P}^{u p} \cdot g_{P V, t} \\
g_{V P P, t}-g_{V P P}^{\min } \geq r_{W P P}^{\text {down }} \cdot g_{W P P, t}+r_{P V}^{\text {down }} \cdot g_{P V, t}
\end{gathered}
$$

In order to ensure the stable operation of VPP, some reserve capacity should be arranged. Therefore, Eq.(32)and Eq.(33) represent system spinning reserve constraint.

(4) Other constraints

As important components of VPP, CGT and ESSs system operation constraints should be considered into the basic mathematical model. CGT operation constraints mainly contain power output constraint, ramping constraint and startup-shutdown time constraint. ESSs operation constraints mainly contain charging-discharging power constraint, charging-discharging statue constraint and ESSs capacity constraint etc. CGT and ESSs operation have already been researched in our previous work [33].

\subsection{Risk aversion model}

Risk aversion model for VPP operation is proposed, which could provide an risk analysis and control tool for different types of system decision makers. Basic mathematical model determined the optimal operation strategy under the objective of the maximum net operation profit. Assume $\boldsymbol{g}_{V P P, t}^{*}$ is the optimal solution and objective value is $f\left(\boldsymbol{g}_{V P P, t}^{*}\right) . \boldsymbol{g}_{V P P, t}^{*}$ contains $\boldsymbol{g}_{W P P, t}^{*}, \boldsymbol{g}_{P V, t}^{*}, \boldsymbol{g}_{E S S, t}^{*}, \Delta L_{i, t}^{E^{*}}, \Delta L_{i, t}^{R, d n^{*}}, \Delta L_{i, t}^{R, u p^{*}}$ and other vectors. However, the result does not consider the risk from uncertainty factors. To overcome the above shortage, this manuscript uses CVaR method and confidence degree theory to build risk aversion model for VPP operation. Considering VPP operation risk brought by uncertainty factors, CVaR theory is used to describe the operation risk. Assume VPP net income is $\Delta R(\boldsymbol{G}, \boldsymbol{g})$, $\boldsymbol{G}^{T}=\left[g_{V P P, t}(1), g_{V P P, t}(2), \cdots, g_{V P P, t}(T)\right]$ is the decision vector and $\boldsymbol{y}^{T}=\left[\boldsymbol{g}_{W P P, t}, \boldsymbol{g}_{P V, t}, \boldsymbol{L}_{t}\right]$ is a multivariate random vector. Then $\Delta R(\boldsymbol{G}, \boldsymbol{g})$ could be described as:

$$
\Delta R(\boldsymbol{G}, \boldsymbol{g})=R(\boldsymbol{G}, \boldsymbol{g})-C(\boldsymbol{G}, \boldsymbol{g})=\left(\begin{array}{l}
P_{W P P, t} g_{W P P, t}+P_{P V, t} g_{P V, t}+P_{E S S, t} g_{E S S, t}+P_{C G T, t} g_{C G T, t}- \\
\rho_{E S S, t}^{c h r} g_{E S S, t}^{c h r}+\left(\pi_{C G T, t}^{p g}+\pi_{C G T, t}^{s s}\right)+\left(\pi_{t}^{\mathrm{PB}}+\pi_{t}^{\mathrm{IB}}\right)+\rho_{U G, t} g_{U G, t}
\end{array}\right)
$$

Define VPP operation loss as $f(\boldsymbol{G}, \boldsymbol{g})=-\Delta R(\boldsymbol{G}, \boldsymbol{g})$, according to Eq. (34). Set the confidence degree $\beta$ and take the net income calculated in Section 4.1 as the threshold, namely $\alpha=-E\left[f\left(\boldsymbol{g}_{V P P, t}\right)\right]=-f\left(\boldsymbol{g}_{V P P, t}^{*}\right)$.The objective function of VPP operation with uncertainty factors is construct in Eq. (35).

$$
F_{\beta}(\boldsymbol{G}, \alpha)=\alpha+\frac{1}{1-\beta} \int_{\boldsymbol{g} \in R^{m}}(f(\boldsymbol{G}, \boldsymbol{g})-\alpha)^{+} p(\boldsymbol{g}) d \boldsymbol{g}
$$

According to Eq. (35), get $N$ sample values $g_{1}, g_{2}, \cdots, g_{N}$ of the random vector $\boldsymbol{g}$ and use the sample value of $F_{\beta}(\boldsymbol{G}, \alpha)$ to instead the expected value [41]: 


$$
F_{\beta}(\boldsymbol{G}, \alpha)=\alpha+\frac{1}{N(1-\beta)} \sum_{k=1}^{N}(f(\boldsymbol{G}, \boldsymbol{g})-\alpha)_{k}^{+}
$$

To simplify the expression, virtual variable $z_{k}=(f(\boldsymbol{G}, \boldsymbol{g})-\alpha)_{k}, k=1,2, \cdots, N$ is introduced. The CVaR model for VPP scheduling considering uncertainty factors is:

$$
\begin{aligned}
& \min \hat{F}_{\beta}(\boldsymbol{G}, \alpha)=\alpha+\frac{1}{N(1-\beta)} \sum_{k=1}^{N} z_{k} \\
& \text { s.t. }\left\{\begin{array}{l}
E q .(20)-E q .(31) \\
E q .(37)-E q .(40) \\
z_{k} \geq 0 \\
\text { other constriants }
\end{array}\right.
\end{aligned}
$$

The model should meet constraint Eq. (20)-(31) and the operation constraints of CGT and ESSs. However, according to Eq. (34) and (35) the objective function of the proposed CVaR model only considers the uncertainties of WPP and PV. The uncertainty of demand load is not considered, which would also influence VPP operation. To overcome the shortage, this manuscript introduces the concept of confidence degree in stochastic chance constrained programming [42] to convert Eq. (20)-(21) and Eq. (32)-(33). The detailed constraints are as follows:

$$
\begin{gathered}
\operatorname{Pr}\left\{g_{V P P, t}+g_{G C, t}=L_{t}^{0}\right\} \geq \beta_{1} \\
\operatorname{Pr}\left\{g_{V P P, t}+g_{G C, t}+\sum_{i=1}^{I}\left(\Delta L_{i, t}^{E}+\Delta L_{i, t}^{R, d n}\right)=L_{t}+\sum_{i=1}^{I}\left(\Delta L_{i, t}^{R, u p}\right)\right\} \geq \beta_{1} \\
\operatorname{Pr}\left(g_{V P P}^{\max }-g_{V P P, t}+\Delta L_{P B, t}+\sum_{i=1}^{I} \Delta L_{i, t}^{E} \geq r_{1} \cdot L_{t}+r_{W P P}^{u p} \cdot g_{W P P, t}+r_{W P P}^{u p} \cdot g_{P V, t}\right) \geq \beta_{2} \\
\operatorname{Pr}\left(g_{V P P, t}-g_{V P P}^{\min } \geq r_{W P P}^{d o w n} \cdot g_{W P P, t}+r_{P V}^{d o w n} \cdot g_{P V, t}\right) \geq \beta_{3}
\end{gathered}
$$

By converting Eq. (37)-(40), the uncertainty factor of demand load could be processed.

\subsection{Solution methodology}

Eq. (40) determined the objective function of VPP risk aversion model. However, according to equation (15), the objective function contains quadratic term, which makes it a Mixed Integer Nonlinear Programming (MINLP). Solving MINLP is complex, need much time and hard to get the optimal solution. Similarly, CGT units operation constraints also contain nonlinear constrain. Therefore, before solving the model, the nonlinear objective function and the nonlinear constraints should be linearized, which has already been researched in our previous work [33]. After the linearization, MINLP model would be converted into a Mixed Integer Linear Programming (MIP) problem. Furthermore, the MIP problem is solved by using CPLEX solver under General Algebraic Modeling System (GAMs) [39] with an idea pad450 series laptop computer powered by a core T6500 processor and 4 GB of RAM. GAMs software could be better to handle with MIP problem for finding the optimal solution with less time. The detailed solving progress is shown in Fig.4.

Fig.4 Model solution methodology flowchart 


\section{Simulation analysis}

\subsection{Scenario set}

To analyze the effectiveness of the proposed model in solving the uncertainty problems of WPP, PV and demand load, this manuscript set three simulation scenarios:

Case 1: Reference scenario, economic scheduling for VPP operation without considering uncertainties. This scenario mainly takes the simulation for the basic scheduling model. The scenario mainly analyzes the operation characteristics of VPP components and calculates the expected net income.

Case 2: CVaR scenario, risk aversion scheduling for VPP operation only with CVaR theory. This scenario mainly takes the simulation for risk aversion scheduling model. The scenario mainly analyzes the applicability of CVaR theory in solving the uncertainties of WPP and PV by comparing the scheduling result with different threshold value $\alpha$. However, the objective function does not include random variable of demand load.

Case 3: Comprehensive scenario, risk aversion scheduling for VPP operation with CVaR theory and confidence degree method. Considering the uncertainty of demand load, this scenario introduces confidence degree method to convert the constraints that contain random variable, analyze VPP scheduling considering multiple uncertainties factors, and compare VPP scheduling results with different threshold value $\alpha$ and confidence degree value $\beta$.

\subsection{Basic data}

To provide case analysis for the proposed model, this manuscript take the improved IEEE30 system as simulation system [43]. $2 \times 1 \mathrm{MW}$ wind turbine and $1 \times 0.5 \mathrm{MW}$ ESSs were assessed at point $30,5 \times 02 . \mathrm{MW}$ PV and $1 \times 1$ MW CGT were assessed at point 29 . The charging power and discharging power of ESSs is not more than $0.04 \mathrm{MW}$ and $0.05 \mathrm{MW}$ [39]. The interruptible load could be regard as adjustable load. Set the load at point 30 as the adjustable load, which could participates into VPP scheduling though IBDR. Set the load at point 29 as the adjustable load, which response system scheduling though PBDR. To avoid the large load fluctuation causing by valley-peak upside down, this paper set the load change produced by PBDR does not exceed $\pm 0.04 \mathrm{MW}$ [37] and the output of IBDR participate into VPP scheduling does not exceed $\pm 0.03 \mathrm{MW}$ [33]. Fig.5 is the improved IEEE30 bus system structure diagram with VPP.

Fig. 5 the improved IEEE30 system structure diagram with VPP

In VPP, the type of CGT mainly is G3406LE with rated output power $1.025 \mathrm{MW}$, which consumes natural gas $107.7 \mathrm{~m}^{3} / \mathrm{h}$ [43]. The startup and shutdown time is $0.1 \mathrm{~h}$ and $0.2 \mathrm{~h}$, the startup and shutdown cost is about 95 Yuan/MW·h. Gas cost function of power generation is a quadratic function, referring to literature [44]. To simplify the solution, Cost function of power generation is linearized into two parts, the slope coefficients of the two parts are 105Yuan/MW and 355Yuan/MW, the loss rate of power generation units is about $2.5 \%$. Assume the cut-in, rated and cut-out wind velocity of WPP are $2.8 \mathrm{~m} / \mathrm{s}, 12.5 \mathrm{~m} / \mathrm{s}$ and $22.8 \mathrm{~m} /$, the shape coefficient is $\varphi=2$ and the scale coefficient is $\vartheta=2 \bar{v} / \sqrt{\pi}$ [44]. According to 
literature [39], set illumination intensity parameters $\xi$ and $\psi$ as 0.3 and 8.54. Considering demand load prediction more accurate than the output of WPP and PV, set the standard deviation of demand load prediction as $0.05 \mathrm{MW}$, while the standard deviation of WPP output and PV output as $0.08 \mathrm{MW}$, respectively. 5 years typical daily demand load data of a sea island in China is taken as the historical data for simulating demand load [33]. When PDFs of wind velocity, radiation intensity and demand load are gain, 50 groups of simulation scenarios would be generated and 10 typical scenarios are get by the proposed scenario simulation method. Scenario with the maximum probability is taken as the input data as shown in Fig.6.

Fig.6 Simulation scenario of WPP, PV and demand load

The grid connection prices of WPP, PV and CGT are $0.56 \mathrm{Yuan} / \mathrm{kW} \cdot \mathrm{h}, 0.5 \mathrm{Yuan} / \mathrm{kW} \cdot \mathrm{h}$ and $0.8 \mathrm{Yuan} / \mathrm{kW} \cdot \mathrm{h}$. The price of VPP purchasing power from public grid is $0.95 \mathrm{Yuan} / \mathrm{kW} \cdot \mathrm{h}$. In order to incentive customers' response to system schedule, TOU price would be implemented. Before PBDR, customers' power consumption price is $0.55 \mathrm{Yuan} / \mathrm{kW} \cdot \mathrm{h}$. After PBDR, power price in float load period keep the same and power price in peak load period increased by $25 \%$ while power price in valley load period decreased by $40 \%$. Electricity price elasticity matrix is set referring to literature [37]. IBDR reserve service price is set as $0.5 \mathrm{Yuan} / \mathrm{kW} \cdot \mathrm{h}$ referring to literature [33]. Charging price and discharging price of ESSs enjoyed TOU price as list in Table 1.

Table. 1 the parameters of PBDR and IBDR

\subsection{Operation results}

\subsubsection{Case 1: VPP scheduling result in reference scenario}

This scenario mainly analyzes the characteristics of VPP components, the complementary effect of CGT, ESSs, WPP and PV as well as the collaborative optimization effect of demand response. VPP scheduling result in Case 1 shows the abandoned wind power and solar photovoltaic power are $0.19 \mathrm{MW} \cdot \mathrm{h}$ and 0.08MW.h, respectively. Fig.7 is the scheduling optimization result in Case 1.

Fig.7 VPP scheduling optimization result in Case 1

According to Fig.7, demand load in peak load period is mainly satisfied by WPP and PV in Case1, while CGT, ESSs and IBDR provide reserve service for WPP and PV. Wherein, the discharges power of ESSs and IBDR provides downwards spinning reserve. In other periods, demand load is mainly satisfied by CGT and WPP, ESSs and IBDR provide reserve service in some periods to increase demand load and improve WPP grid connection space. For example, IBDR provides upwards spinning reverse from 6:00 to 10:00 and ESSs charges from 0:00 to 10:00. The output of CGT, WPP and PV are 8.125MW·h, 9.13MW.h and 3.36MW.h. Furthermore, to analyze the influence of ESSs and demand response on VPP operation, this manuscript simulates VPP scheduling with/without ESSs, IBDR and PBDR. System net load covers in different scenarios is shown in Fig.8.

Fig.8 System net demand load curve with/without ESS, IBDR and PBDR

According to Fig.8, compared with original demand load, ESS, IBDR and PBDR could guide 
customers to shift their power consumption period and realize peak-valley shifting. Where, IBDR could effectively reduce peak load, but its valley filling capability is not as good as PBDR. Though ESSs and PBDR could reduce peak load, their reduction effect is not as good as IBDR. When ESSs and DR are both introduced, demand load curve would be smoothed to the maximum extend. The peak-valley ratios of the five curves are 1.58, 1.49, 1.49, 1.4 and 1.31. Wherein, compared with original demand load curve, the maximum value and minimum value of demand load with ESSs and DR are changed $\pm 0.07 \mathrm{MW}$, respectively. The scheduling optimization results in different scenarios are shown in Table 2.

Table.2 System scheduling optimization results under different scenario in Case 1

According to Table.2, ESSs, IBDR and PBDR could reduce the peak-valley ratio of demand load curve and increase WPP output. However, compared with introduction one of the above units, when they are all introduced, the output of WPP and PV would reach the maximum, namely $9.13 \mathrm{MW} \cdot \mathrm{h}$ and $3.36 \mathrm{MW} \cdot \mathrm{h}$, respectively. Relatively the net income of VPP operation comes to the maximum, $¥ 9550.19$, which is $¥ 525.31$ more than that without ESSs and DR. VPP incremental gains in other scenarios could be seen in Fig.9.

Fig.9 VPP operation net income change compared with No (DR, ESSs) scenario

According to Fig.9, PBRD has peak-valley shifting capability in peak load period. VPP output and VPP income decreased. But IBDR provide downwards spinning reverse and ESSs discharge, which increased VPP income. When they are both introduced, VPP operation income increases obviously. In valley load period, VPP income increases, which mainly because DR shifted load, ESSs discharges in some periods and IBDR provide upwards/downwards spinning reserve. In valley load period, DR and ESSs could increase demand load, improve grid connection of WPP and PV and increase VPP operation income. But if only introduce ESSs to storage energy from WPP output and PV output, which would not generate incremental grid connection and income. The incremental income of VPP operation is relatively small.

\subsubsection{Case 2: VPP scheduling result in CVaR scenario}

Different from Case 1, uncertainties are considered in Case 2. This scenario mainly analyzes the effectiveness of CVaR theory in processing the risk brought by uncertainty factors. Set threshold value $\alpha$ in Case 2 as 0.9 time of VPP operation net income with ESSs and DR. That means, considering the uncertainties, VPP net income is less than $\alpha$ and risk happens. Assume the confidence degree $\beta=0.95$, then scheduling result of VPP operation considering uncertainties is shown in Fig.10.

Fig.10 VPP operation scheduling result in Case 2

Compared with Fig.7, if considering uncertainties, WPP output and PV output are relatively less in peak load period, the abandoned wind power and solar photovoltaic power are $0.67 \mathrm{MW} \cdot \mathrm{h}$ and $0.29 \mathrm{MW} \cdot \mathrm{h}$. CGT units are arranged to meet demand load and CGT output increases from 8.125MW.h to 8.94MW.h. This indicates that uncertainty factors bring risks, which would decrease the output of WPP and PV. CGT would be called to meet demand load. Similarly, the reduced output of WPP and PV decreases the requirement on reserve service of ESSs and IDR, which makes reserve service of IBDR and ESSs less than 
Case 1.Furthermore, to analyze the influence of different threshold on VPP scheduling, VPP operation incomes with threshold changed $\pm 15 \%, \pm 10 \%$ and $\pm 5 \%$ are calculated as shown in Fig. 11 .

Fig.11 VPP operation scheduling income with different rate of $\alpha$ change

According to Fig.11, VPP operation income decreases when the threshold increases. This indicates CVaR method could be used to describe risk level bought by uncertainty factors. The threshold value reflects the risk attitude of decision maker. When threshold is small, decision maker has strong risk tolerance and is willing to bear certain risks to get relatively high income. On the contrary, when the threshold is big, decision maker has weak risk tolerance and is unwilling to bear the risk brought by excess income. Table 3 is VPP operation scheduling optimization result with different threshold value.

Table.3 VPP operation scheduling result with different threshold value

According to Table.3, the threshold would influence VPP scheduling result directly. When threshold is relatively high, decision maker would reduce the output of WPP and PV and increase CGT output. Reserve service produced by ESSs and IBDR would reduce, which makes peak-valley ratio is relatively high. When threshold is relatively low, decision maker would increase the output of WPP and PV to get excess income. Reserve service produced by would increase and peak-valley ratio decreased. Risk tolerance of decision maker decreases when $\alpha$ increase, VPP operation income and CVaR value decreases. Fig. 12 shows the output of WPP and PV with different threshold $\alpha$.

Fig.12 the output of WPP and PV with different rate of $\alpha$ change

According to Fig.12, system decreases the output of WPP and PV in peak load period when $\alpha$ increase, which could reduce power shortage. CGT units would be called to meet demand load. In valley load period, demand load is relatively less, which puts less pressure on system scheduling. Power system has sufficient reserve capacity. Therefore the output of WPP and PV do not change. In float load period, WPP output decreased slightly from $2.9 \mathrm{MW} \cdot \mathrm{h}$ to $2.4 \mathrm{MW} \cdot \mathrm{h}$ to minimize VPP operation risk.

\subsubsection{Case 3: VPP scheduling result in comprehensive scenario}

In Case 2, CVaR method considers the random variables in objective function, namely the uncertainties of WPP and PV. The uncertainty influence of demand load on VPP operation is not considered. Therefore, this case processes the random variables in constraints and builds a VPP operation scheduling model considering the uncertainty of WPP, PV and demand load. Set confidence degree vector $\boldsymbol{\beta}=\left[\beta_{1}, \beta_{2}, \beta_{3}, \beta_{4}\right]=0.95$, Fig. 13 is VPP operation scheduling result in Case 3.

Fig.13 VPP operation scheduling result in Case 3

Compared with Fig.10, if not considering the uncertainty of demand load, VPP operation risk would increase. To avoid VPP operation risk, decision maker would further reduce the output of WPP and PV and increase CGT output. CGT output increased by $1.251 \mathrm{MW} \cdot \mathrm{h}$, while abandoned wind power and solar photovoltaic power are $1.10 \mathrm{MW} \cdot \mathrm{h}$ and $0.35 \mathrm{MW} \cdot \mathrm{h}$, respectively. Reserve service provided by IBDR and ESSs would decrease since the output of WPP and PV decreases. The upwards/downwards spinning reverse provided by IBDR are $0.06 \mathrm{MW} \cdot \mathrm{h}$ and $-0.14 \mathrm{MW} \cdot \mathrm{h}$, the charging and discharging power of ESSs are 
$\pm 0.14 \mathrm{MW} \cdot \mathrm{h}$. Then, to analyze the influence of different confidence degree on VPP operation, sets $\boldsymbol{\beta}=0.80$, 0.85, 0.90, 0.95, 0.99 to discuss VPP operation net income under different threshold $\alpha$, as shown in Fig.14.

Fig.14 VPP operation net income with different $\alpha$ and $\beta$ in Case 3

According to Fig.14, risk tolerant of decision maker would decrease when confidence degree $\boldsymbol{\beta}$ increases. Decision maker would reduce the output of WPP and PV, which decrease VPP income. When $\boldsymbol{\beta}$ $\leqslant \mathbf{0 . 8 5}$, the declining degree of VPP operation income is not obvious, which means decision maker can bear risk to get exceed income. When $0.85 \leqslant \boldsymbol{\beta} \leqslant 0.95$, VPP operation income increases obviously, which means decision maker is sensitive to risk. When $\boldsymbol{\beta} \geqslant 0.95$, VPP operation income decreased slightly, which means VPP scheduling scheme reached most conservative level. Then, the output of WPP and PV under different $\boldsymbol{\beta}$ and $\boldsymbol{\alpha}$ is calculated as shown in Fig.15.

Fig.15 Wind power ( $a$ ) and solar photovoltaic power $(b)$ output in Case 3 with different $\alpha$ and $\beta$

According to Fig. 15 , when $0.85 \leqslant \boldsymbol{\beta} \leqslant 0.95$ decision maker reduced WPP output and PV output to the maximum extent to reduce VPP operation risk and system power shortage cost. When $\boldsymbol{\beta} \leq 0.85$, decision maker has relatively less sensitive toward risk, which makes declining degree of WPP output and PV output is relatively less. When $\boldsymbol{\beta} \geq 0.95$, VPP operation scheme is almost most conservative, which means the influence of confidence degree increase on the output of WPP and PV is small. CVaR value of VPP operation under different confidence degree and threshold value are calculated as shown in Fig.16.

Fig.16 CVaR value of VPP operation with different $\alpha$ and $\beta$ in Case 3

According to Fig. 16 , CVaR reflects the risk level of VPP scheduling directly. When $0.85 \leqslant \boldsymbol{\beta} \leqslant 0.95$, the decreasing slope of CVaR value is relatively big, which means the sensitive degree of decision maker toward risk is relatively high. When $\boldsymbol{\beta} \leq 0.85$, the decreasing slope of $\mathrm{CVaR}$ value is relatively small, which means the sensitive of decision maker toward risk is relatively low, and decision maker is willing to bear risk to for excess income. When $\boldsymbol{\beta} \geq 0.9$, though decision make has high sensitive toward risk, VPP operation scheme has already reached the most conservative level, which makes the decreasing slope of CVaR value relatively small. The above result shows CVaR method and confidence degree theory could effectively describe VPP operation risk level, decision maker could set reasonable threshold and confidence degree to realize the maximum income with lowest risk.

\subsection{Comparatively analysis}

This section comparatively analyzes VPP operation result including VPP output, net demand load curve, operation income and risk level in different scenarios. Table.4 is VPP operation scheduling results in different cases.

Table.4 VPP operation scheduling results in different cases

For VPP output, derived by the maximum profit objective, the output of WPP and PV reached the maximum in Case 1. To ensure system stable operation, IBDR and ESSs also reach the maximum. However, 
this scenario does not take the output of WPP and PV into consideration. VPP scheduling operation with the scheme in Case 1 would bring big risk. Case 2 and Case 3 consider the uncertainty influence of WPP output and PV output. Case 3 also consider the uncertainty influence of demand load. When VPP operation considers the uncertainty factors, WPP output and PV output would reduce, the abandoned wind power and solar photovoltaic power in Case 2 and Case 3 are 0.67MW.h, 0.295MW'h and 1.10MW.h, 0.35MW.h, relatively. Fig. 17 is net demand load curve in different cases.

Fig.17 Net demand load curve in different cases

For CGT output, when considering uncertainties, CGT output increase obviously. That means system would reduce WPP output and PV output, increase CGT output to reduce VPP operation risk. Especially in peak load period, to reduce the risk of supply and demand imbalance risk, CGT output increased from 2.54MW' $\mathrm{h}$ to $3.06 \mathrm{MW} \cdot \mathrm{h}$ in Case 2 and $3.39 \mathrm{MW} \cdot \mathrm{h}$ in Case 3. In valley load period, to reduce the influence of the volatility of WPP and PV, demand load is relatively low and CGT output increase. In float load period CGT output almost keep the same. Table.5 is VPP operation income and risk level in different cases.

Table.5 VPP operation income and risk level in different cases

For system net demand load, IBDR and ESSs is scheduled at the greatest extent in Case1, which brings the most obvious peak-valley shifting effect and the peak-valley ratio of the net demand load curve reached the minimum point, namely 1.31. However, WPP output and PV output reached their maximum value, which means VPP is facing with big operation risk. Case 3 has the biggest peak-valley ratio of net demand load, namely 1.41. That is because WPP output and PV output are limited, IBDR and ESSs are scheduled in shallow degree. But VPP operation risk in Case 3 is the smallest. Compared with the original demand load curve, ESSs and DR could reduce peak load and increase valley load, the peak-valley ratio reduce. VPP operation scheme would be optimized and the operation risk would be reduced.

For VPP operation income and risk, compared with Case 2 and Case 3, if not considering the uncertainty influence of demand load, CVaR value in Case 3 would be less than Case 2. That means if considering the uncertainty demand load, VPP operation risk would decrease by reducing WPP output and PV output. System net income would reduce by 8995.34 Yuan. This means decision maker have to decrease VPP operation income to avoid risk cost. On the contrary, decision maker has to bear the corresponding risk to get excess income. That is to say, CVaR method and confidence degree theory could provide decision support tool for decision maker to balance income and risk, realize VPP optimization operation.

\section{Conclusions}

In order to make full use of distributed energy, WPP, PV, CGT, ESSs, IBDR are aggregated into VPP in the paper. CVaR method and confidence degree theory are introduced to overcome the uncertainty influence of WPP, PV and load on VPP operation. Basic economical scheduling model for VPP operation is constructed without uncertainties under the objective of the maximum VPP operation net revenue. While, in order to analyze the uncertainty risk, risk aversion scheduling model is construct for VPP operation with the objective of the minimum risk level considering the maximum VPP operation net based on the CVaR 
method and the confidence degree theory. The improved IEEE30 bus system is taken as simulation system. The follows conclusions could be gained by the simulation results :

(1) The proposed risk aversion model for VPP operation could provide a risk decision tool for different types of system decision maker. CVaR method and confidence degree theory could describe uncertainty factors in objective function and constraint conditions. When decision maker prefer to risk average, they will reduce the output of WPP and PV, correspondingly, the net revenue of VPP operation is less. Otherwise, they are willing to bear certain risk to gain the excess income by increasing the output of WPP and PV, correspondingly, the net revenue of VPP operation is high.

(2) If not considering risk, WPP and PV are mainly used to satisfy demand load for maximizing VPP operation income since the marginal costs of WPP and PV are almost zero. IBDR, PBDR and ESSs could all reduce peak-valley ration of load curve and promote the net VPP operation revenue. IBDR has better peak load clipping effect, while ESSs and PBDR has better valley load filling effect. In peak load period, PBDR decreases demand load, IBDR provides downwards spinning reverse and ESSs discharges power. In float load period, demand load is relatively stable, VPP operation income changes slightly. In valley load period, PBDR generates incremental load, IBDR provides upwards spinning reverse and ESSs charges power. When they are all introduced, the whole result of VPP operation reaches the maximum.

(3) If considering risk and only bringing CVaR theory, the output of WPP and PV are relatively less in peak load period, CGT would be called to meet demand load. CVaR method could describe the influence of uncertainty factors on VPP operation, but only considers the uncertainty factors in the objective function. The threshold reflects the risk attitude of decision maker. When the threshold is relatively low, decision maker has strong risk tolerant and willing to bear certain risk to gain the excess income. When the threshold is relatively high, decision maker has weak risk tolerant and unwilling to bear the risk brought by WPP and PV. In peak load period, system would reduce WPP output and PV output to averse the loss brought by power shortage. However, in other period, demand load is less and system has sufficient reserve capacity, WPP output and PV output almost unchanged.

(4) The confidence degree theory can overcome the shortage of CVaR method by converting the constraints with uncertainty factors. When $\boldsymbol{\beta}$ (confidence degree) $\leq 0.85$, the declining rate of WPP and PV is small and the decreasing slope of CVaR value is relatively small, which means decision maker is not sensitive on risk and willing to bear certain risk to gain excess income. When $0.85 \leq \boldsymbol{\beta} \leq 0.95$, the decreasing slope of CVaR value is relatively big, which means decision maker is sensitive on risk and will reduces WPP output and PV output to avoid risk and loss. When $\boldsymbol{\beta} \geq 0.9$, the change of $\boldsymbol{\beta}$ has little influence on WPP and PV, the decreasing slope of CVaR value is relatively small, which means VPP scheduling scheme reached the most conservative. Overall, The decision maker should set reasonable threshold and confidence degree according to their risk attitude to maximize VPP operation income with the minimum risk level.

\section{Acknowledgement}

The work is partially supported by the National Science Foundation of China (Grant No: 71273090, 71573084), the Fundamental Research Funds for the Central Universities (2016XS72). 


\section{References}

[1] Sreekanth M, Herbert FL. Energy technology allocation for distributed energy resources: A strategic technology-policy framework [J]. Energy, 2014, 72: 783-799

[2] Jonas K, Frits MA, Poul EM. Load-shift incentives for household demand response: Evaluation of hourly dynamic pricing and rebate schemes in a wind-based electricity system [J]. Energy, 2016, 115: $1602-1616$

[3] Ahmad N, Jamshid A, Mohammad M. Managing the risk of uncertain wind power generation in flexible power systems using information gap decision theory[J].Energy, 2016, 114: 846-861

[4] Valentin R, Georgios C, Ramachandra K, et al. Rewarding cooperative virtual power plant formation using scoring rules[J]. Energy, 2016,117: 19-28

[5] Rahiminejad A, Vahidi B, Hejazi MA, et al. Optimal scheduling of dispatchable distributed generation in smart environment with the aim of energy loss minimization [J]. Energy, 2016, 116: 190-201.

[6] European virtual fuel cell power plant management summary report [EB/OL]. [2012-08-13]. htpp:ec.europa.eu/energy/efficiency/industry/doc/euvpp.pdf/

[7] Francesco Rossi, David Velázquez. A methodology for energy savings verification in industry with application for a CHP (combined heat and power) plant[J]. Energy, 2015, 89: 528-544

[8] Dong WL, Wang Q, Yang L.A coordinated dispatching model for distribution utility and virtual power plants with wing/photovoltaic/hydro generators [J]. Automation of Electric Power System, 2015, 39(9):75-82.

[9] Nikonwical, Mileskij. Virtual power plant-general review: structure, application and optimization [J]. Journal of power technologies, 2012,92(3):135-149

[10] Mostafa SA, Seth B, Andrew K. Estimating zonal electricity supply curves in transmission-constrained electricity markets [J].Energy, 2015,80:10-19

[11] Yu S, Wei ZH, Sun GQ, et al. A bidding model for a virtual power plant considering uncertainties [J]. Automation of Electric Power System, 2014, 38(22): 44-49.

[12] Project interim report[R/OL].[2013-02-20].http://www.web2energy.com/

[13] Miadreza SK, Mohsen PM, Mohamad KS, et al. Modeling of interactions between market regulations and behavior of plug-in electric vehicle aggregators in a virtual power market environment[J].Energy, 2012, 40(1): 139-150

[14] Okan A, Oya EK. Cost and emission impacts of virtual power plant formation in plug-in hybrid electric vehicle penetrated networks[J].Energy, 2013, 60: 116-124

[15] Mohammad AT, Ashkan RK, Alireza S. Risk averse optimal operation of a virtual power plant using two stage stochastic programming[J].Energy, 2014, 73: 958-967

[16] Hropko D, Ivanecky J, Turcek J. Optimal dispatch of renewable energy sources included in virtual power plant using accelerated particle swarm optimization[C]//2012 ELEKTRO. Rajeck Teplice,

Slovakia: IEEE, 2012: 196-200

[17] Peik-Herfeh M, Seifi H, Sheikh-El-Eslami MK. Decision making of a virtual power plant under uncertainties for bidding in a day-ahead market using point power estimate method [J]. Intentional 
Journal of Electric Power and energy system, 2013, 44:88-98

[18] Pandzic H, Kuzle I, Capuder T. Virtual power plant mid-term dispatch optimization [J]. Applied Energy, 2013, 101: 134-41

[19] Zapata J, Vandewalle J, D'haeseleer W. A comparative study of imbalance reduction strategies for virtual power plant operation [J]. Applied Thermal Engineering, 2014, 71: 847-857

[20] Carrion M, Arroyo JM. A computationally efficient mixed-integer linear formulation for the thermal unit commitment problem [J]. IEEE Transaction on Power System 2006, 21(3):1371-1378.

[21] Mohammad MJ, Ahad K. Demand side management in a smart grid with multiple electricity suppliers[J].Energy, 2015, 81: 766-776

[22] Gao DC, Sun YG, Lu YH. A robust demand response control of commercial buildings for smart gridunder load prediction uncertainty[J].Energy, 2015,93: 275-283

[23] Siwar K, Mouna R, Lotfi K. A flexible control strategy of plug-in electric vehicles operating in seven modes for smoothing load power curves in smart grid[J].Energy, 2017,118: 197-208

[24] Stjepan S, Tomislav D, Tomislav C, et al. Economic dispatch of virtual power plants in an event-driven service-oriented framework using standards-based communications [J].Electric Power Systems Research, 2011, 81: 2108-2119.

[25] Wang D, Parkinson S, Miao W, et al. Hierarchical market integration of responsive loads as spinning reserve[J]. Applied Energy, 2013(104): 229-238.

[26] Erdinc O. Economic impacts of small-scale own generating and storage units and electric vehicles under different demand response strategies for smart households [J]. Applied Energy, 2014, 126, $142-150$.

[27] Hossein S, Ashkan RK. A cost-efficient and reliable energy management of a micro-grid using intelligent demand-response program [J]. Energy, 2015,91;105: 283-293

[28] Ziogou C, Ipsakis D, Seferlis P, et al. Optimal production of renewable hydrogen based on an efficient energy management scheme [J]. Energy, 2013, 55:58-67.

[29] Moghaddam IG, Nick M, Fallahi F, et al. Risk-averse profit based optimal operation scheme of a combined wind frame cascade hydro system in an electricity market [J].Renewable Energy $2013,55: 252-259$.

[30] Saeed RD, Mohammad K, Sheikh EE., Risk-based profit allocation to DERs integrated with a virtual power plant using cooperative game theory [J].Electric Power Systems Research, 2015, 121: 368-378

[31] Molderink A, Bakker V, Bosman MGC, Management and control of domestic smart grid technology [J].IEEE Transaction on Smart Grid, 2010, 1(2): 109-119

[32] Yang HM, Yi DX, Zhao JH, et al. Distributed optimal dispatch of virtual power plant based on ELM transformation[J]. Management, 2014, 10(4): 1297-1318

[33] Ju Lw, Tan ZF, Yuan JY, et al. A bi-level stochastic scheduling optimization model for a virtual power plant connected to a wind-photovoltaic-energy storage system considering the uncertainty and demand response[J].Applied Energy ,2016,171: 184-199

[34] Mohammad AT, Ashkan RK, Alireza S. Risk averse optimal operation of a virtual power plant using 
two stage stochastic programming [J]. Energy, 2014, 73: 958-967

[35] Tascikaraoglu A, Erdinc O, Uzunoglu M, et al. An adaptive load dispatching and forecasting scheme for a virtual power plant including renewable energy conversion units [J]. Applied Energy, 2014, 119: $445-453$

[36] Guo L,Wang N, Lu H, et al. Multi-objective optimal planning of the stand-alone microgrid system based on different benefit subjects[J].Energy, 2016, 116: 353-363

[37] Tan ZF, Ju LW, Li HH, etal. A two-stage scheduling optimization model and solution algorithm for wind power and energy storage system considering uncertainty and demand response [J]. International Journal of Electrical Power and Energy Systems, 2014, 63: 1057-1069

[38] Rodolfo DL, Eduardo PC, José LB, etal. Optimization of energy supply at off-grid healthcare facilities using Monte Carlo simulation [J]. Energy Conversion and Management, 2016, 113: 321-330

[39] Tan ZF, Li HH, Ju LW, etal. An Optimization Model for Large-Scale Wind Power Grid Connection Considering Demand Response and Energy Storage Systems[J].energies, 2014, 7(11): 7282-7304

[40] Growe KN, Heitsch H, Romisch W. Scenario reduction and scenario tree construction for power management problems [D]. Proceeding of IEEE power tech conference, Bologna, Italy, June 23-26, 2003

[41] Sebastian M, Alexandre S, Ken M. Risk-averse portfolio selection of renewable electricity generator investments in Brazil: An optimized multi-market commercialization strategy[J].Energy, 2016,115: $1331-1343$

[42] Saeed K, Mostafa K, Mehdi E. Equilibrium in the competitive retail electricity market considering uncertainty and risk management[J].Energy, 2016,106:315-328

[43] Fan SL, Ai Q, He X. Risk Analysis on Dispatch of Virtual Power Plant Based on Chance Constrained Programming[J].Proceedings of the CSEE, 2015, 35(16): 4025-3034

[44] Ippolito MG, Di-Silvestre ML, Riva SE, et al. Multi-objective optimized management of electrical energy storage systems in an islanded network with renewable energy sources under different design scenarios[J].Energy, 2014, 64: 648-662 


\section{Nomenclature}

\begin{tabular}{|c|c|c|c|}
\hline \multicolumn{2}{|c|}{ Abbreviations } & \multirow{2}{*}{$\frac{r_{P V}^{\text {down }}}{\beta_{1}}$} & \multirow{2}{*}{$\begin{array}{l}\text { downward reserves coefficient of PV } \\
\text { confidence degree level of demand load } \\
\text { supply and demand balance constraint }\end{array}$} \\
\hline VPP & Virtual power plant & & \\
\hline WPP & Wind power plant & $\beta_{2}$ & upwards spinning reverse constraint \\
\hline PV & Photovoltaic generators & $\beta_{3}$ & downwards spinning reverse constraint \\
\hline CGT & Convention gas turbine & $\alpha$ & threshold value \\
\hline ESS & Energy storage systems & \multicolumn{2}{|l|}{ Variable } \\
\hline CVaR & Conditional value at risk & $g_{W P P, t}$ & wind power output at time $t$ \\
\hline IBDR & Incentive-based demand response & $v_{t}$ & natural income wind velocity at time $t$. \\
\hline PBDR & Price-based demand response & $g_{P V, t}$ & output power of solar photovoltaic at time $t$ \\
\hline DGs & Distributed generators & $\theta_{t}$ & $\begin{array}{l}\text { radiation intensity of photovoltaic panel at } \\
\text { time } t\end{array}$ \\
\hline DERs & Distributed energy resources & $L_{t}$ & demand load at time $t$ \\
\hline DRPs & Demand response Providers & $\pi_{t}^{\mathrm{PB}}$ & cost of price-based demand response \\
\hline PDF & Probability distribution function & $e_{s t}$ & demand-price elastic \\
\hline VG & virtual generation & $\pi_{t}^{\mathrm{IB}}$ & cost of incentive-based demand response \\
\hline \multicolumn{2}{|c|}{ Parameter } & $\rho_{i, t}^{E}$ & $\begin{array}{l}\text { cost of DPR } i \text { participating in demand-side } \\
\text { reserve scheduling at time } t\end{array}$ \\
\hline$v$ & wind velocity & $\Delta L_{i, t}^{E}$ & load reduction of DPR $i$ at time $t$ \\
\hline$\varphi$ & $\begin{array}{l}\text { shape parameter of Weibull } \\
\text { distribution }\end{array}$ & $\rho_{i, t}^{R, d n}$ & $\begin{array}{l}\text { cost of DPR } i \text { participating in down } \\
\text { demand-side reserve scheduling }\end{array}$ \\
\hline$\vartheta$ & $\begin{array}{l}\text { scale parameter of Weibull } \\
\text { distribution }\end{array}$ & $\rho_{i, t}^{R, d n}$ & $\begin{array}{l}\text { cost of DPR } i \text { participating in up } \\
\text { demand-side reserve scheduling }\end{array}$ \\
\hline$v_{\text {in }}$ & income wind velocity & $\Delta L_{i, t}^{R, d n}$ & $\begin{array}{l}\text { down demand-side reserve of DPR } i \text { at time } \\
t\end{array}$ \\
\hline$v_{\text {out }}$ & cutout wind velocity & $\Delta L_{i, t}^{R, u p}$ & up demand-side reserve of DPR $i$ at time $t$ \\
\hline$v_{\text {rated }}$ & rated wind velocity & $\boldsymbol{g}_{V P P, t}$ & VPP output at time $t$ \\
\hline$g_{R}$ & rated WPP output & $R\left(\boldsymbol{g}_{V P P, t}\right)$ & revenue of VPP power generation \\
\hline$\xi, \psi$ & shape parameters of Beta distribution & $C\left(\boldsymbol{g}_{V P P, t}\right)$ & cost of VPP power generation \\
\hline$\mu$ & mean value of solar irradiance & $g_{W P P, t}$ & WPP output at time $t$ \\
\hline$\sigma$ & standard deviation of solar irradiance & $g_{P V, t}$ & PV output at time $t$ \\
\hline$\eta_{P V}$ & $\begin{array}{l}\text { energy conversion efficiency of } \\
\text { photovoltaic panel }\end{array}$ & $g_{E S S, t}$ & ESS output at time $t$ \\
\hline$S_{P V}$ & area of photovoltaic panel & $g_{C G T, t}$ & CGT output at time $t$ \\
\hline$L_{t}^{\mathrm{f}}$ & load prediction results & $g_{E S S, t}^{c h r}$ & storage energy of ESSs at time $t$ \\
\hline$L_{t}^{\mathrm{e}}$ & load prediction error & $g_{U G, t}$ & $\begin{array}{l}\text { power quantity of ESSs purchasing from } \\
\text { public grid at time } t\end{array}$ \\
\hline$P_{t}$ & electric price after PBDR & $\pi_{C G T, t}^{p g}$ & operation cost of CGT at time $t$ \\
\hline
\end{tabular}




\begin{tabular}{|c|c|c|c|}
\hline$P_{t}^{0}$ & electric price before PBDR & $\pi_{C G T, t}^{s s}$ & startup-shutdown cost of CGT at time $t$ \\
\hline$L_{t}$ & demand load after PBDR & $\begin{array}{l}a_{C G T}, b_{C G T}, \\
c_{C G T}\end{array}$ & cost coefficient of CGT generation \\
\hline$L_{t}^{0}$ & demand load before PBDR & $u_{C G T, t}$ & operation statue of CGT at time $t$ \\
\hline$\rho_{k}$ & probability of scenario $k$ & $D_{C G T, t}$ & startup-shutdown cost of CGT at time $t$ \\
\hline$P_{W P P, t}$ & WPP output tariff at time $t$ & $T_{C G T, t}^{\text {off }}$ & continuous downtime of CGT at time $t$ \\
\hline$P_{P V, t}$ & PV output tariff at time $t$ & $\Delta L_{P B, t}$ & load change after PBDR at time $t$ \\
\hline$P_{E S S, t}$ & ESS output tariff at time $t$ & $D_{i, t}^{j}$ & $\begin{array}{l}\text { deployed load curtailment of DRP } i \text { in step } j \\
\text { at time } t\end{array}$ \\
\hline$P_{C G T, t}$ & CGT output tariff at time $t$ & $\Delta L_{i, t}^{E}$ & load reduction of DPR $i$ at time $t$ \\
\hline$\rho_{E S S, t}^{c h r}$ & charging tariff of ESSs at time $t$ & $\Delta L_{i, t}^{j}$ & load reduction of DPR $i$ in step $j$ at time $t$ \\
\hline$\rho_{U G, t}$ & $\begin{array}{l}\text { power tariff of ESSs purchasing from } \\
\text { public grid }\end{array}$ & $\Delta L_{i, t}^{R, d n}$ & $\begin{array}{l}\text { down/demand-side reserve of DPR } i \text { at time } \\
t\end{array}$ \\
\hline$N_{C G T}^{\text {hot }}$ & hot-startup cost of CGT & $\Delta L_{i, t}^{R, u p}$ & $\begin{array}{l}\text { up demand-side reserve of DPR } i \text { at time } t \text {, } \\
\text { respectively }\end{array}$ \\
\hline$N_{C G T}^{\text {cold }}$ & cold-startup cost of CGT & $g_{V P P, t}$ & VPP output at time $t$ \\
\hline$T_{C G T}^{\min }$ & $\begin{array}{l}\text { minimum allowable downtime of } \\
\text { CGT }\end{array}$ & $\Delta L_{P B, t}$ & load change produced by PBDR at time $t$ \\
\hline$T_{C G T}^{\text {cold }}$ & cold startup time of CGT & $F_{\beta}(X, \alpha)$ & CVaR value of the portfolio problem \\
\hline$\Delta \underline{L}_{P B}$ & $\begin{array}{l}\text { pickup rate of load produced by } \\
\text { PBDR }\end{array}$ & $\beta$ & confidence degree \\
\hline$\Delta \bar{L}_{P B}$ & $\begin{array}{l}\text { drop off rate of load produced by } \\
\text { PBDR }\end{array}$ & $\psi(\boldsymbol{X}, \alpha)$ & $\begin{array}{l}\text { distribution function of the cumulative loss } \\
\text { with portfolio vector } \boldsymbol{X}\end{array}$ \\
\hline$\Delta L_{P B}^{\max }$ & $\begin{array}{l}\text { accumulative maximum limitation of } \\
\text { load fluctuation }\end{array}$ & $\boldsymbol{\Omega}$ & $\begin{array}{l}\text { subset of } n \text {-dimension real-number space } \\
\boldsymbol{R}^{n}\end{array}$ \\
\hline$D_{i}^{j, \min }$ & $\begin{array}{l}\text { minimum acceptable load reduction of } \\
\text { DPR } i \text { in step } j\end{array}$ & $p(\boldsymbol{Y})$ & joint probability density function of $\boldsymbol{Y}$ \\
\hline$D_{i}^{\max }$ & $\begin{array}{l}\text { maximum acceptable load reduction } \\
\text { of DPR } i \text { in step } j\end{array}$ & Set & \\
\hline$D_{i}^{\min }$ & $\begin{array}{l}\text { minimum acceptable load reduction of } \\
\text { DPR } i \text { in step } j\end{array}$ & $s, t$ & index for time, $s, t=1,2, \ldots \ldots, T$. \\
\hline$g_{V P P, t}^{\max }$ & maximum power of VPP output & $i$ & index for DPR \\
\hline$g_{V P P, t}^{\min }$ & minimum power of VPP output & $k$ & index for scenarios \\
\hline$r_{1}$ & system reverse coefficient & $W P P$ & index for WPP \\
\hline$r_{W P P}^{u p}$ & upwards reserves coefficient of WPP & $P V$ & index for PV \\
\hline$r_{W P P}^{\text {down }}$ & $\begin{array}{l}\text { downward reserves coefficient of } \\
\text { WPP }\end{array}$ & $C G T$ & index for CGT \\
\hline$r_{P V}^{u p}$ & upwards reserves coefficient of PV & ESS & index for ESSs \\
\hline
\end{tabular}


Table. 1 the parameters of PBDR and IBDR

\begin{tabular}{|c|c|c|c|c|c|c|}
\hline \multirow{2}{*}{} & \multicolumn{3}{|c|}{ PBDR } & \multicolumn{3}{c|}{ IBDR } \\
\cline { 2 - 6 } & Peak load period & Valley load period & Float load period & Energy market & Reserve market \\
\cline { 2 - 6 } & $12: 00-21: 00$ & $0: 00-3: 00 ; 21: 00-24: 00$ & $3: 00-12: 00$ & - & Up & Down \\
\hline Time divide & 0.69 & 0.33 & 0.55 & 0.5 & 0.2 & 0.6 \\
\hline $\begin{array}{c}\text { Power price } \\
\text { (Yuan/kW·h) }\end{array}$ & & & & & 0.2 \\
\hline
\end{tabular}

Table.2 System scheduling optimization results under different scenario in Case 1

\begin{tabular}{|c|c|c|c|c|c|c|c|c|c|}
\hline \multirow{2}{*}{ Scenario } & \multicolumn{5}{|c|}{ VPP power output/MW·h } & \multicolumn{3}{|c|}{ Demand load/MW } & \multirow{2}{*}{ Benefit/\# } \\
\hline & CGT & WPP & PV & IBDR & ESS & Peak & Valley & Peak-valley ratio & \\
\hline Without ESSs and DR & 8.604 & 8.89 & 3.08 & 0 & 0 & 0.95 & 0.60 & 1.58 & 9024.88 \\
\hline Only with ESS & 8.505 & 8.99 & 3.10 & $\overline{0}$ & \pm 0.23 & 0.93 & 0.63 & 1.49 & 9125.36 \\
\hline Only with IBDR & 8.487 & 9.03 & 3.12 & $(0.09,-0.12)$ & 0 & 0.91 & 0.61 & 1.49 & 9240.45 \\
\hline Only with PBDR & 8.494 & 9.06 & 3.12 & 0 & 0 & 0.91 & 0.64 & 1.42 & 9330.64 \\
\hline With PBDR and IBDR & 8.418 & 9.08 & 3.17 & $(0.09,-0.14)$ & 0 & 0.89 & 0.63 & 1.41 & 9441.23 \\
\hline With ESSs and PBDR & 8.323 & 9.09 & 3.22 & 0 & \pm 0.25 & 0.90 & 0.65 & 1.38 & 9480.21 \\
\hline With ESSs and IBDR & 8.326 & 9.10 & 3.25 & $(0.10,-0.18)$ & \pm 0.27 & 0.90 & 0.66 & 1.37 & 9385.45 \\
\hline With ESSs and DR & 8.125 & 9.13 & 3.36 & $(0.11,-0.22)$ & \pm 0.30 & 0.88 & 0.67 & 1.31 & 9550.19 \\
\hline
\end{tabular}

Table.3 VPP operation scheduling result with different threshold value

\begin{tabular}{|c|c|c|c|c|c|c|c|c|c|c|}
\hline \multirow{2}{*}{$\begin{array}{c}\text { rate of } \alpha \\
\text { change }\end{array}$} & \multicolumn{5}{|c|}{ VPP power output/MW·h } & \multicolumn{2}{|c|}{ Abandoned power/MW'h } & \multirow{2}{*}{$\begin{array}{c}\text { Peak-valley } \\
\text { ratio }\end{array}$} & \multirow{2}{*}{$\begin{array}{c}\text { Benefit } \\
/ ¥\end{array}$} & \multirow{2}{*}{$\begin{array}{c}\text { CVaR } \\
/ ¥\end{array}$} \\
\hline & CGT & WPP & $\mathrm{PV}$ & ESS & IBDR & WPP & PV & & & \\
\hline$-15 \%$ & 9.32 & 8.95 & 3.31 & $(0.09,-0.20)$ & \pm 0.28 & 0.37 & 0.14 & 1.38 & 9330 & 33240 \\
\hline$-10 \%$ & 8.45 & 8.86 & 3.27 & $(0.08,-0.19)$ & \pm 0.25 & 0.47 & 0.17 & 1.39 & 9235 & 28732 \\
\hline$-5 \%$ & 8.57 & 8.77 & 3.24 & $(0.08,-0.18)$ & \pm 0.23 & 0.56 & 0.21 & 1.40 & 9158 & 23581 \\
\hline 0 & 8.94 & 8.66 & 3.15 & $(0.07,-0.16)$ & \pm 0.22 & 0.67 & 0.29 & 1.41 & 9085 & 19001 \\
\hline $5 \%$ & 9.08 & 8.49 & 3.13 & $(0.06,-0.15)$ & \pm 0.20 & 0.84 & 0.31 & 1.42 & 9025 & 14549 \\
\hline $10 \%$ & 9.25 & 8.30 & 3.07 & $(0.06,-0.14)$ & \pm 0.19 & 1.03 & 0.38 & 1.44 & 8945 & 10520 \\
\hline $15 \%$ & 9.36 & 8.11 & 3.02 & $(0.05,-0.13)$ & \pm 0.15 & 1.21 & 0.45 & 1.45 & 8885 & 5705 \\
\hline
\end{tabular}

Table.4 VPP operation scheduling results in different cases

\begin{tabular}{|c|c|c|c|c|c|c|c|c|c|c|}
\hline & \multicolumn{4}{|c|}{ VPP power output/MW·h } & \multicolumn{2}{c|}{ Abandoned energy/MW·h } & \multicolumn{3}{c|}{ CGT power output/MW·h } \\
\cline { 2 - 11 } & CGT & WPP & PV & IBDR & ESS & WPP & PV & Peak & Float & Valley \\
\hline Case 1 & 8.125 & 9.13 & 3.36 & $(0.11,-0.22)$ & \pm 0.30 & 0.19 & 0.08 & 2.54 & 3.70 & 1.89 \\
\hline Case 2 & 8.941 & 8.66 & 3.15 & $(0.07,-0.16)$ & \pm 0.22 & 0.67 & 0.29 & 3.06 & 3.75 & 2.13 \\
\hline Case 3 & 9.376 & 8.22 & 3.09 & $(0.06,-0.14)$ & \pm 0.14 & 1.10 & 0.35 & 3.39 & 3.75 & 2.24 \\
\hline
\end{tabular}

Table.5 VPP operation income and risk level in different cases

\begin{tabular}{|c|c|c|c|c|c|c|c|c|}
\hline \multirow{2}{*}{ Scenario } & \multicolumn{2}{|c|}{ Demand load/MW } & \multirow{2}{*}{$\begin{array}{c}\text { Peak-valley } \\
\text { ratio }\end{array}$} & \multicolumn{2}{|c|}{ VPP net revenue/Yuan } & \multirow{2}{*}{ VaR/Yuan } & \multirow{2}{*}{ CVaR/Yuan } \\
\cline { 2 - 2 } & Peak & Valley & Revenue & Cost & Net & & \\
\hline Case 1 & 0.88 & 0.67 & 1.31 & 11683 & 2132.81 & 9550.19 & - & - \\
\hline Case 2 & 0.89 & 0.65 & 137 & 11432.26 & 2347.01 & 9085.25 & 8962 & 19001 \\
\hline Case 3 & 0.90 & 0.64 & 1.41 & 11456.54 & 2461.2 & 8995.34 & 8237 & 18834 \\
\hline
\end{tabular}




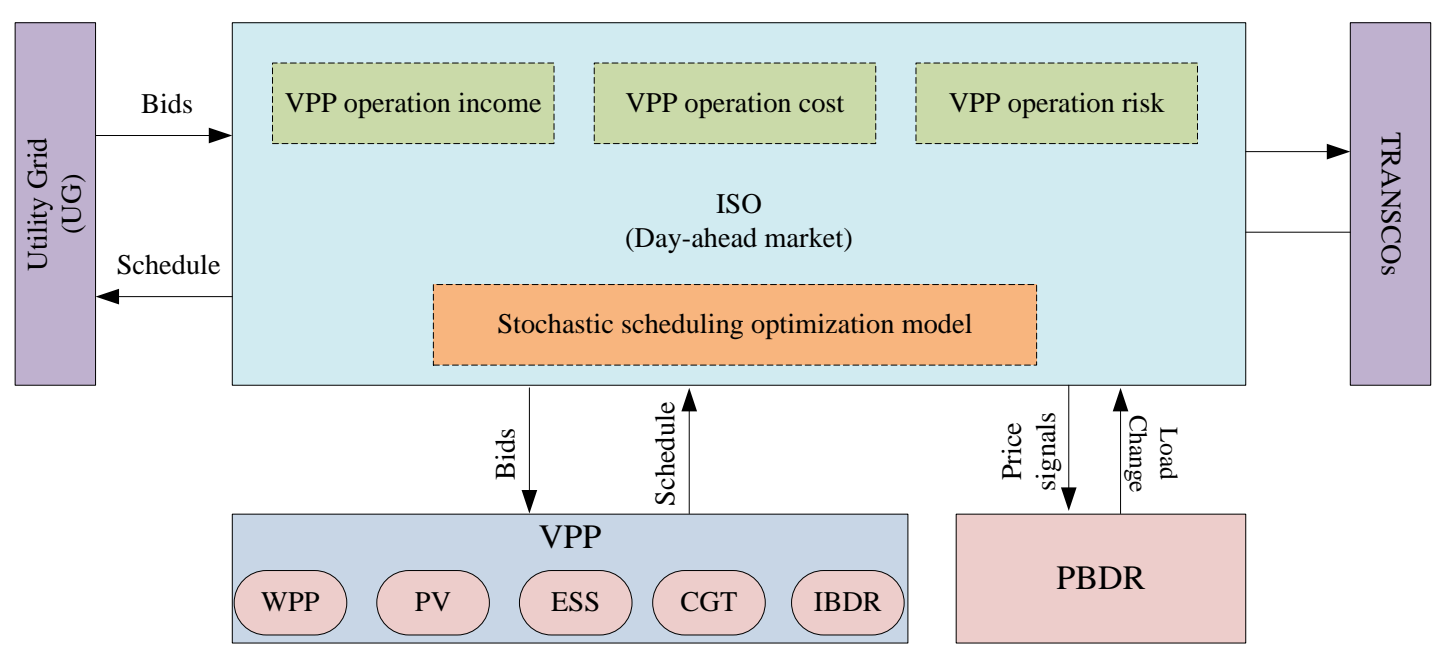

Fig.1 The basic structure of VPP

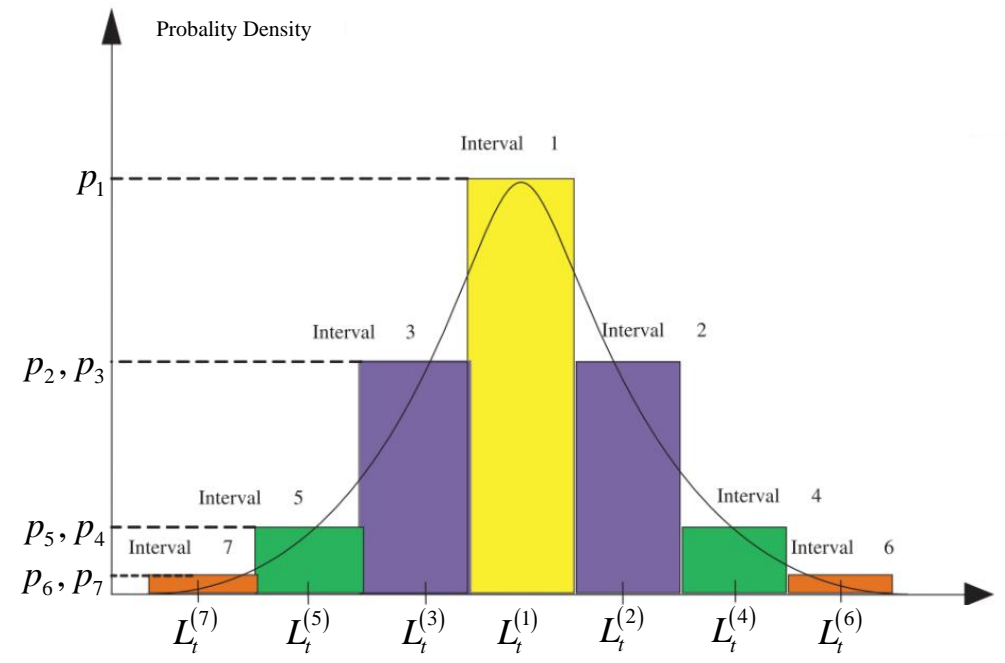

Fig. 2 The discretization method for demand load distribution function

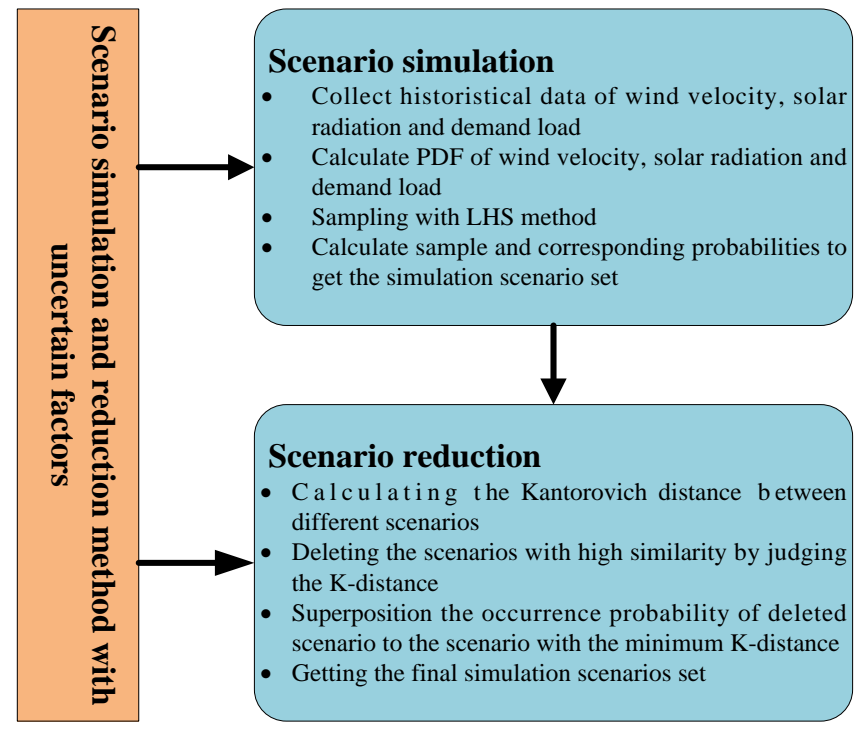

Fig.3 The process of scenario simulation and reduction for uncertainty factors 


\begin{tabular}{|c|c|c|}
\hline Uncertainty analysis and simulation of VPP & & Basic model for VPP scheduling \\
\hline $\begin{array}{l}\text { Collect history data of wind speed, solar irradiation } \\
\text { and load demand; } \\
\text { Construct PDFs of wind speed, solar irradiation } \\
\text { and load demand with Eq.(1), Eq.(3)-(5), Eq.(7); } \\
\text { Construct output models of WPP and PV with } \\
\text { Eq.(2)-(6); } \\
\text { Generate simulation scenarios by Latin Hypercube } \\
\text { Sampling method(LHS) method; } \\
\text { Curtail simulation scenarios by using K-distance } \\
\text { technology. }\end{array}$ & & $\begin{array}{l}\text { Construct PBDR and IBDR model with Eq.(8)-(11) } \\
\text { Formulate objective function for basic model, } \\
\text { namely maximum expected value of net revenue } \\
\text { (Eq. (12)-(17)) } \\
\text { Construct the MINLP model constraints: } \\
\text { (1) supply and demand balance(Eq.(18)-(19)) } \\
\text { (2) demand response operation(Eq.(10)-(29)) } \\
\text { (3) system spinning reserve(Eq.(30)-(31)) } \\
\text { (4) CGT and ESS operation constraints }\end{array}$ \\
\hline Risk aversion model for VPP scheduling & & Model solution methodology \\
\hline $\begin{array}{l}\text { Introduce the basic theory of CVaR method } \\
\text { Construct revenue loss function of VPP operation } \\
\text { Formulate objective function for risk aversion } \\
\text { model(Eq.(38)/Eq.(39)) } \\
\text { Transfer constraints with uncertain factors using } \\
\text { confidence methods (Eq.(41)-(44)) } \\
\text { Take result of basic model of VPP scheduling as } \\
\text { threshold value of revenue loss function } \\
\text { Set confidence for objective function, constraints }\end{array}$ & threshold $\alpha$ & $\begin{array}{l}\text { Linear objective function and constraint conditions } \\
\text { Transfer MINLP model into MIP model after } \\
\text { linearizing nonlinear terms } \\
\text { Solve the proposed model by using CPLEX with } \\
\text { GAMs soft ware } \\
\text { Solve the Problem using a core T6500 processor } \\
\text { and } 4 \text { GB of RAM } \\
\text { Set different simulation scenarios by adjusting } \\
\text { threshold value and confidence }\end{array}$ \\
\hline
\end{tabular}

Fig.4 Model solution methodology flowchart

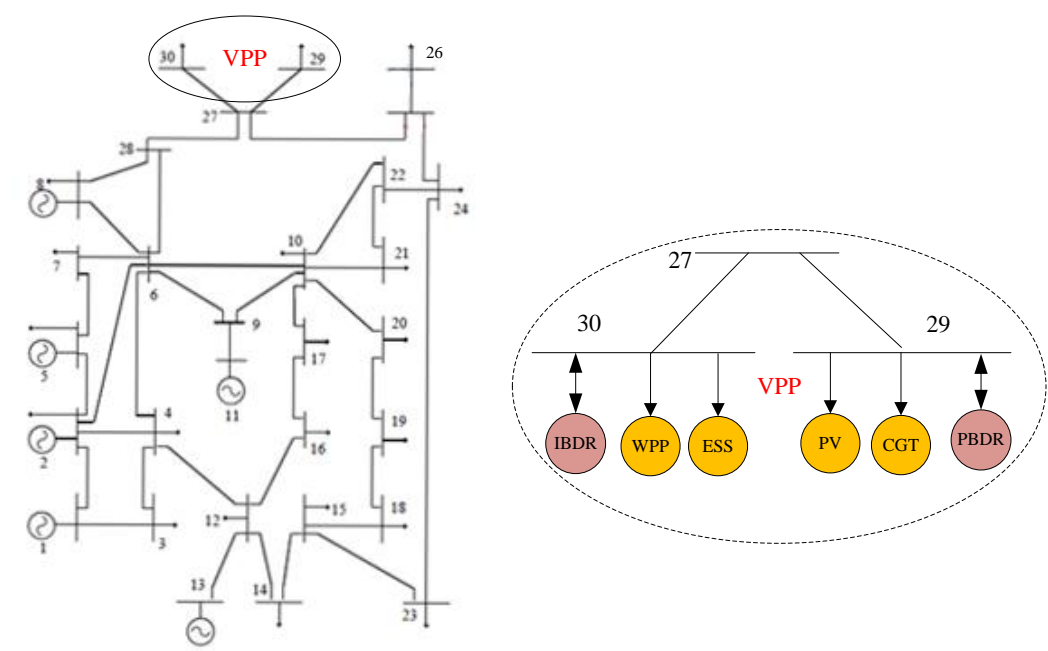

Fig. 5 the improved IEEE30 system structure diagram with VPP

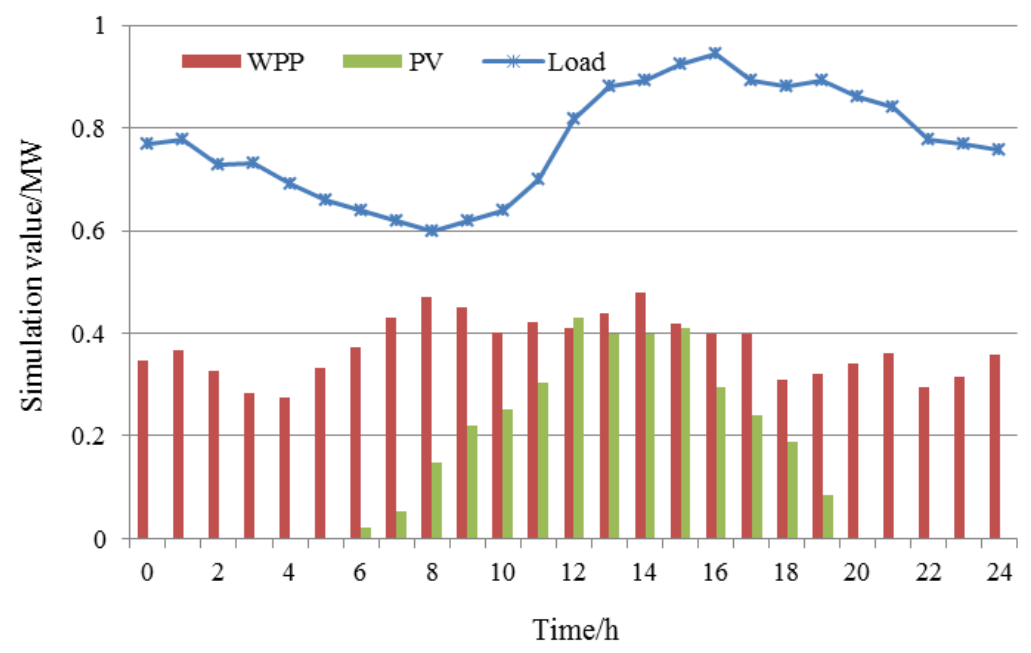

Fig.6 Simulation scenario of WPP, PV and demand load 


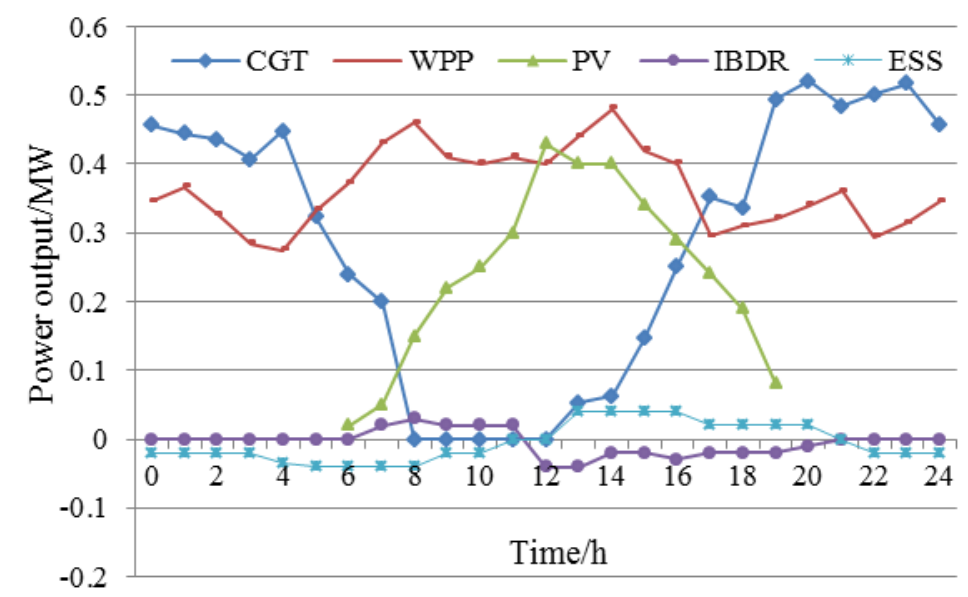

Fig.7 VPP scheduling optimization result in Case 1

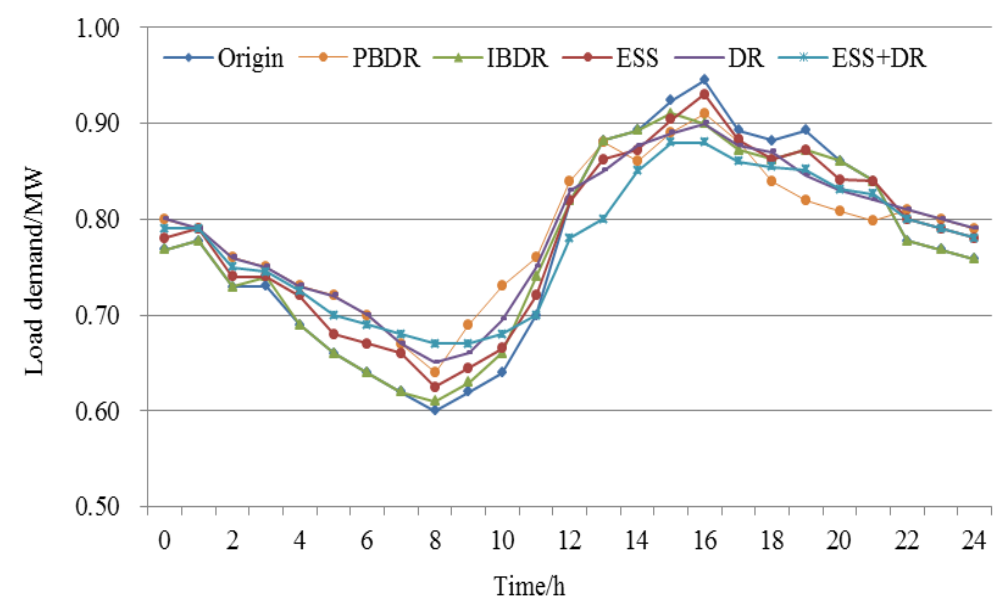

Fig.8 System net demand load curve with/without ESS, IBDR and PBDR

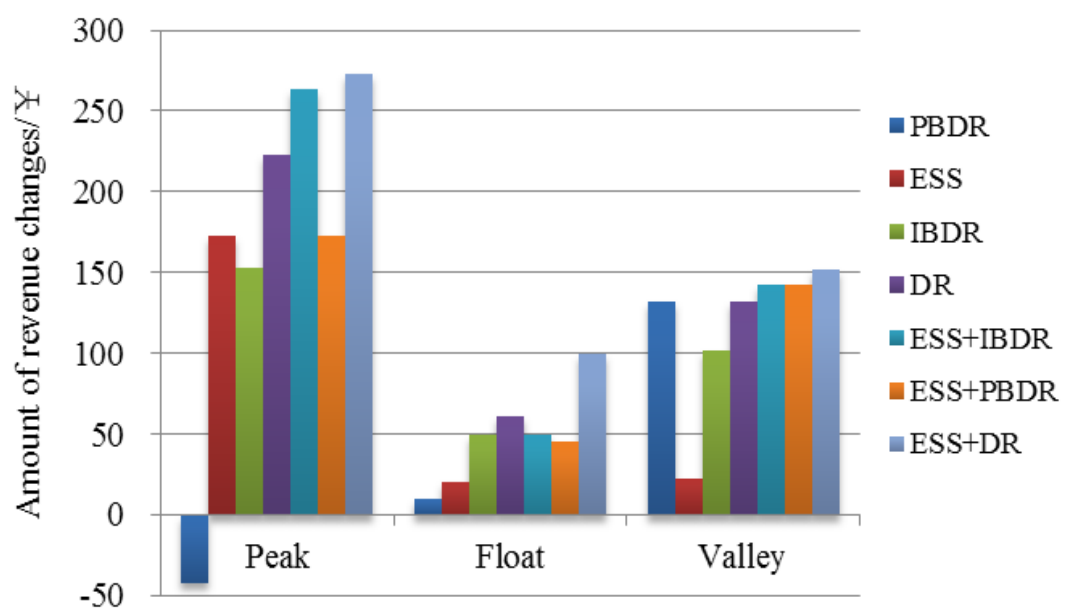

Fig.9 VPP operation net income change compared with No (DR, ESSs) scenario 


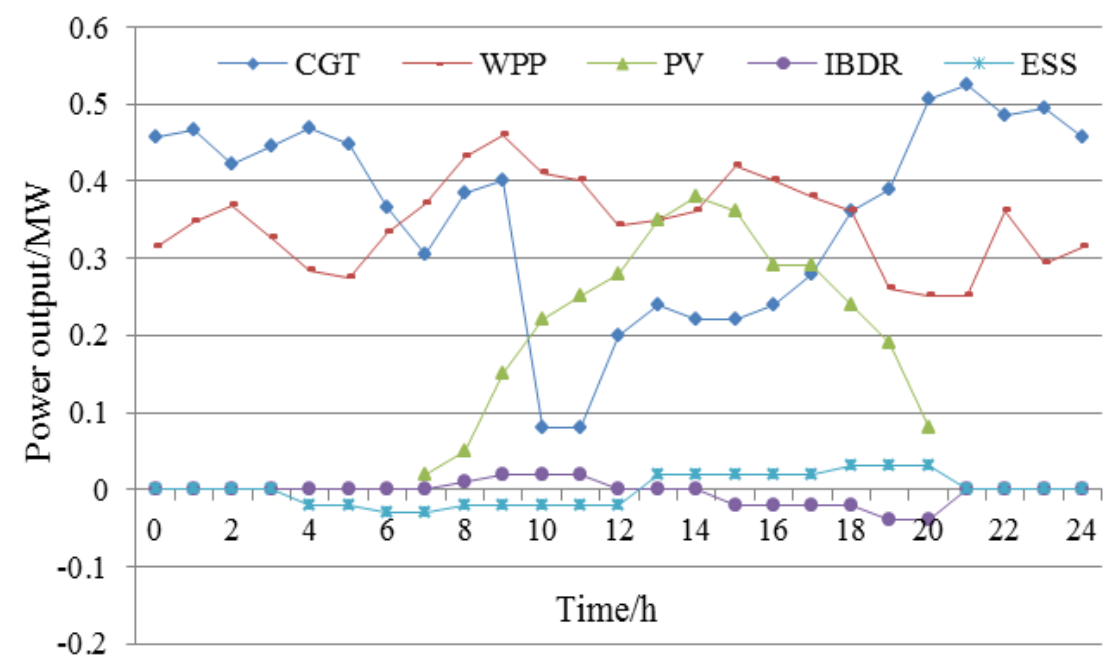

Fig.10 VPP operation scheduling result in Case 2

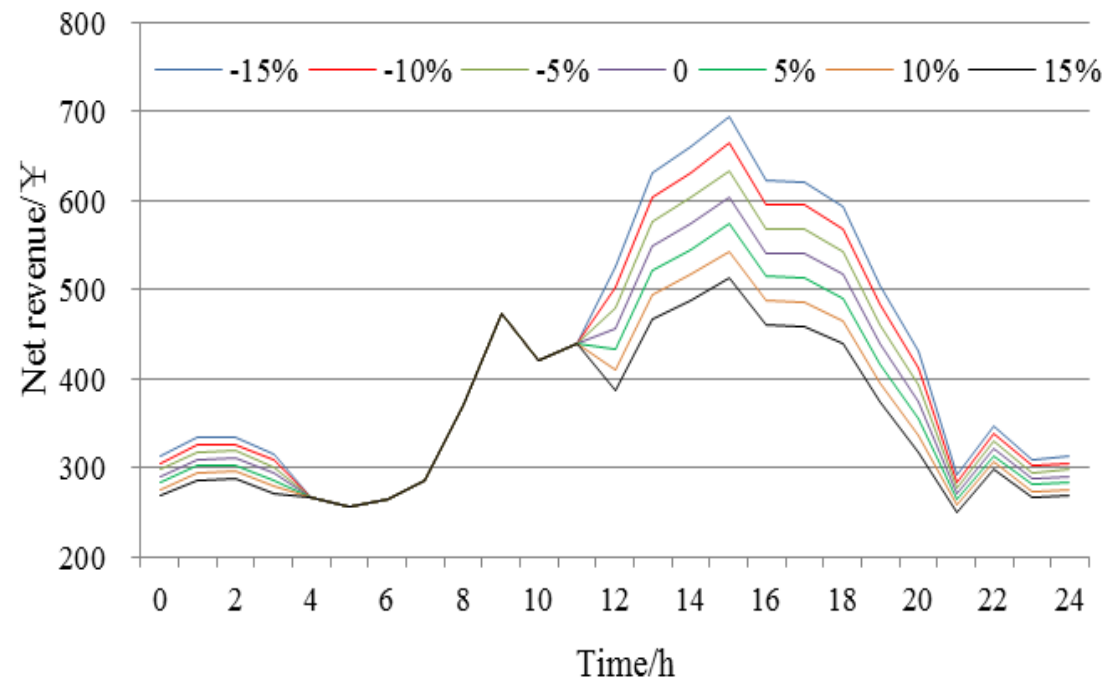

Fig.11 VPP operation scheduling income with different rate of $\alpha$ change

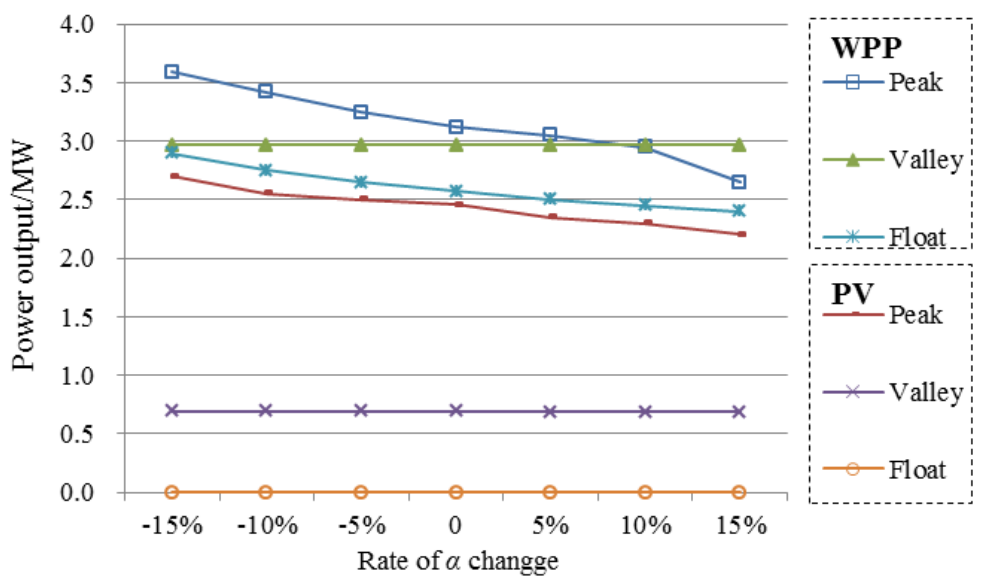

Fig.12 the output of WPP and PV with different rate of $\alpha$ change 


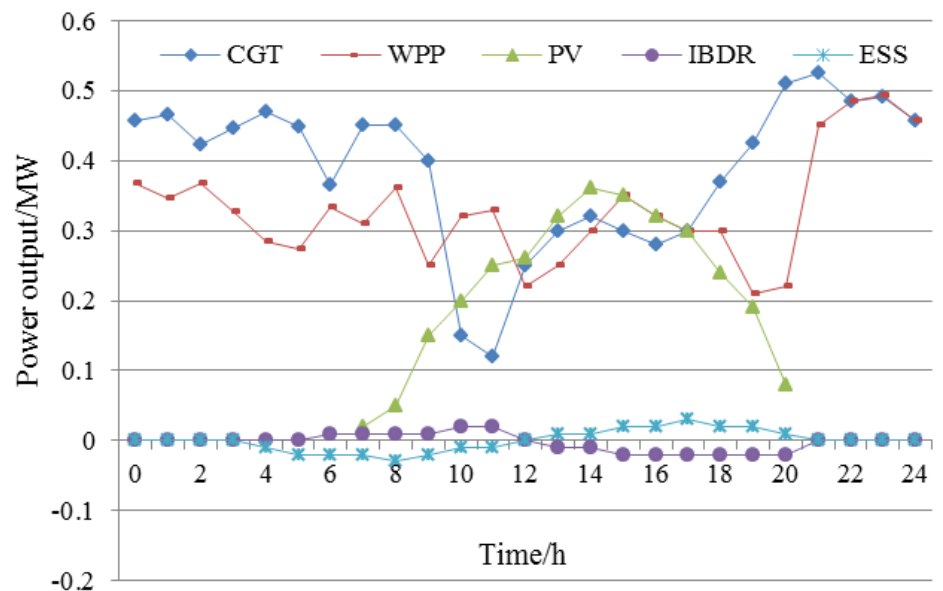

Fig.13 VPP operation scheduling result in Case 3

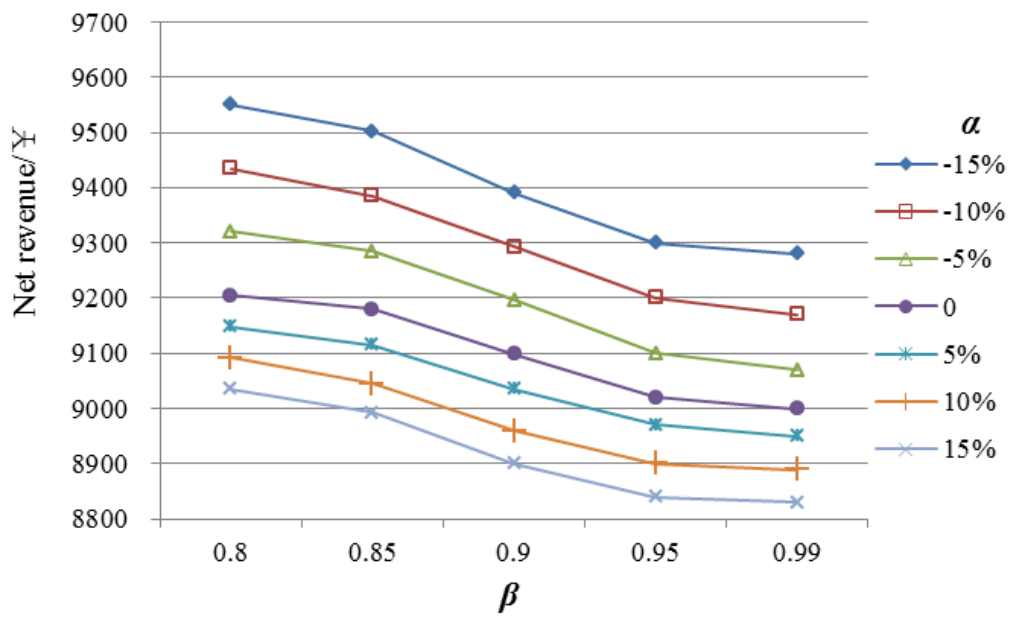

Fig.14 VPP operation net income with different $\alpha$ and $\beta$ in Case 3

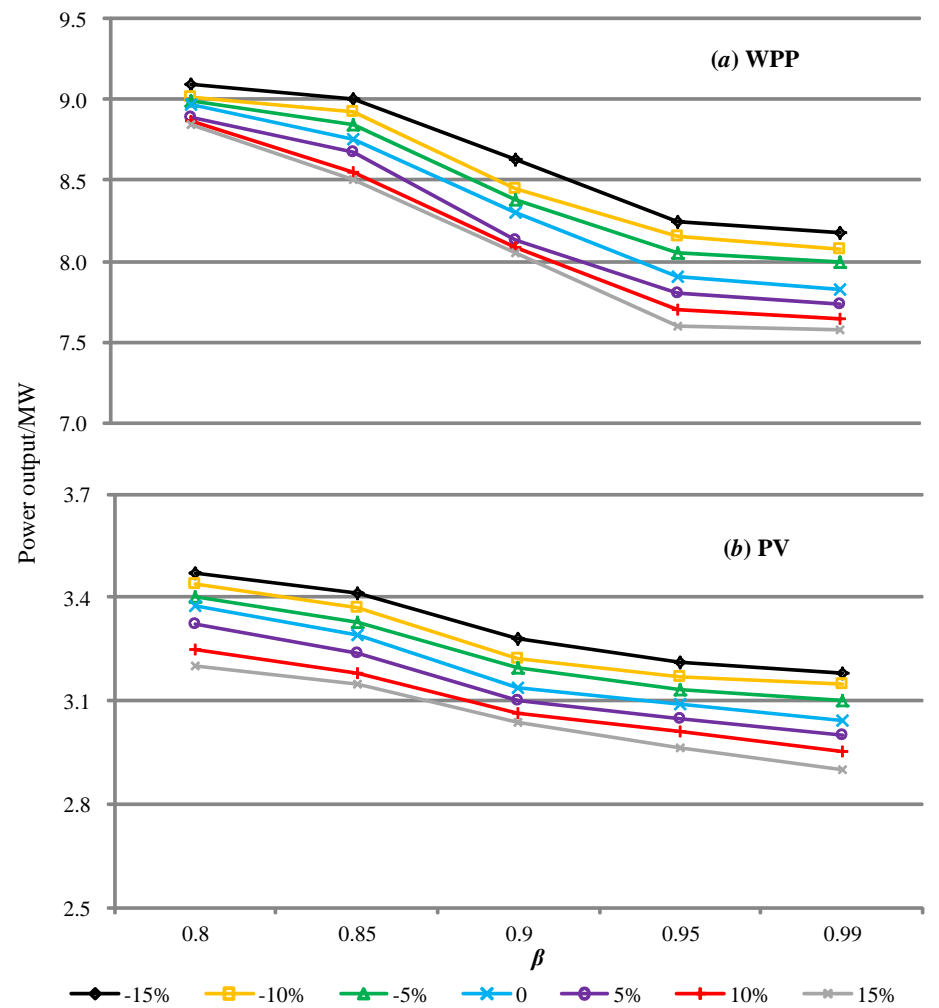

Fig.15 Wind power $(a)$ and solar photovoltaic power $(b)$ output in Case 3 with different $\alpha$ and $\beta$ 


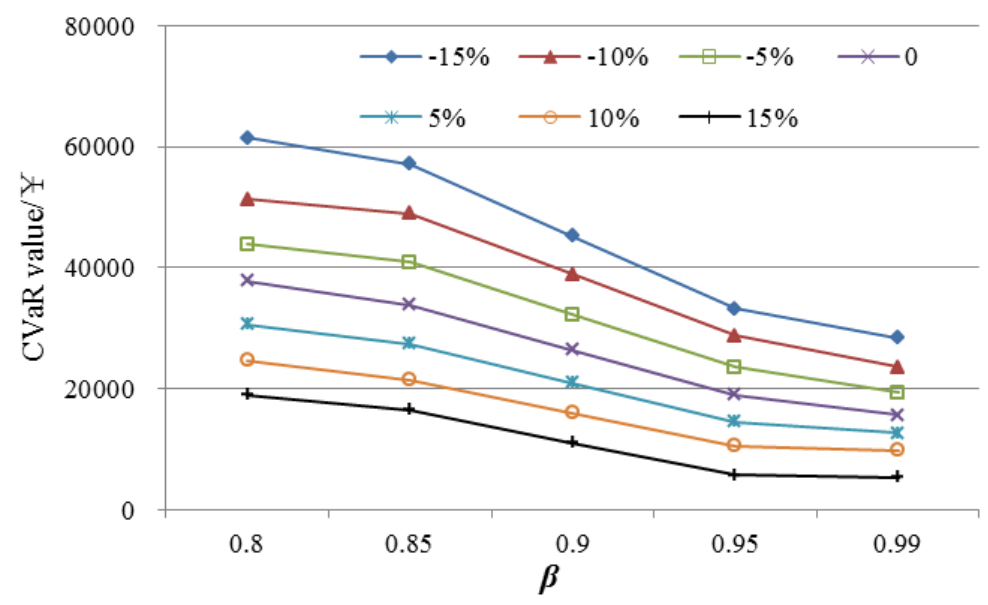

Fig.16 CVaR value of VPP operation with different $\alpha$ and $\beta$ in Case 3

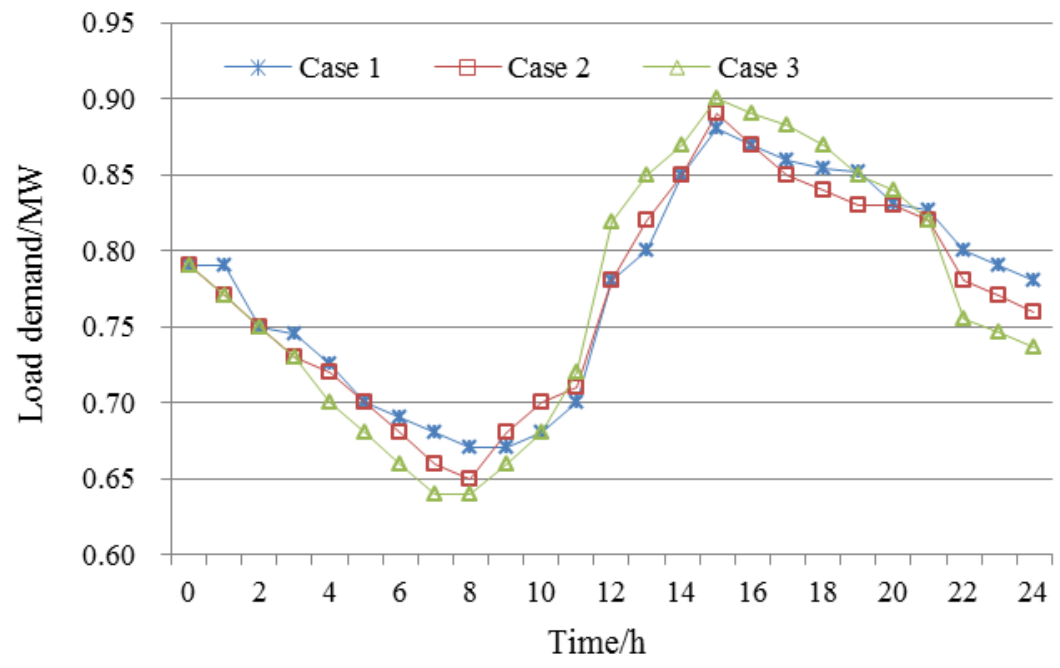

Fig.17 Net demand load curve in different cases 